\title{
The role of the southward wind shift in both, the seasonal synchronization and duration of ENSO events
}

\author{
Esteban Abellán ${ }^{1}$ (D) Shayne McGregor ${ }^{1,2}$
}

Received: 19 March 2015 / Accepted: 24 September 2015 / Published online: 30 October 2015

(C) The Author(s) 2015. This article is published with open access at Springerlink.com

\begin{abstract}
Near the end of the calendar year, when El Niño events typically reach their peak amplitude, there is a southward shift of the zonal wind anomalies, which were centred around the equator prior to the event peak. Previous studies have shown that ENSO's anomalous wind stresses, including this southward shift, can be reconstructed with the two leading EOFs of wind stresses over the tropical Pacific. Here a hybrid coupled model is developed, featuring a statistical atmosphere that utilises these first two EOFs along with a linear shallow water model ocean, and a stochastic westerly wind burst model. This hybrid coupled model is then used to assess the role of this meridional wind movement on both the seasonal synchronization as well as the duration of the events. It is found that the addition of the southward wind shift in the model leads to a Christmas peak in variance, similar to the observed timing, although with weaker amplitude. We also find that the added meridional wind movement enhances the termination of El Niño events, making the events shorter, while this movement does not appear to play an important role on the duration of La Niña events. Thus, our results strongly suggest that the meridional movement of ENSO zonal wind anomalies is at least partly responsible for seasonal synchronization of ENSO events and the duration asymmetry between the warm (El Niño) and cool (La Niña) phases.
\end{abstract}

Esteban Abellán

esteban.abellan@unsw.edu.au

1 ARC Centre of Excellence for Climate System Science and Climate Change Research Centre, University of New South Wales, Sydney, NSW, Australia

2 School of Earth, Atmosphere and Environment, Monash University, Clayton, VIC, Australia
Keywords ENSO $\cdot$ Southward wind shift $\cdot$ Seasonal synchronization $\cdot \mathrm{HCM} \cdot$ Termination $\cdot$ Asymmetry

\section{Introduction}

The El Niño-Southern Oscillation (ENSO) phenomenon is the main driver of Earth's interannual climate variability (Neelin et al. 1998; McPhaden et al. 2006), leading to significant changes in the global atmospheric circulation (Ropelewski and Halpert 1989; Philander 1990; Trenberth et al. 1998; Wang et al. 2003). ENSO refers to a year-toyear recurring warming (El Niño) and cooling (La Niña) of the eastern and central tropical Pacific sea surface temperature (hereafter SST), and a related large-scale seesaw in atmospheric sea level pressure between the Australia-Indonesian region and the south-central tropical Pacific (Bjerkness 1969; Wyrtki 1975; Cane and Zebiak 1985; Graham and White 1988).

El Niño and La Niña events typically last for about a year and have an irregular period ranging between 2 and 7 years. As every winter or summer is different in the extratropics, ENSO events come in many different flavours (Trenberth and Stepaniak 2001). However, they generally follow a similar pattern of developing during boreal spring (MAM), peaking in boreal winter (DJF) and decay during boreal spring of the following year (Rasmusson and Carpenter 1982; Larkin and Harrison 2002; Chang and Coauthors 2006). Understanding the physical processes responsible of such seasonal synchronization is of central importance to predictions (Balmaseda et al. 1995; Torrence and Webster 1998), simulations (Ham et al. 2013) as well as impacts of ENSO, which depend on the characteristics of the events (Trenberth 1997). 
However, the dynamics underlying ENSO synchronization to the annual cycle is not yet understood. Recently, Stein et al. (2014) classified existing theories into two possible categories: (1) frequency locking of ENSO, as a nonlinear oscillator, to periodic forcing by the annual cycle (e.g., Jin et al. 1994; Tziperman et al. 1994); or (2) the modulation of the stability of ENSO due to the seasonal variation of the background state of the equatorial Pacific (Philander et al. 1984; Hirst 1986). Their results suggest that the annual modulation of the coupled stability of the equatorial Pacific ocean-atmosphere system is by far the more likely mechanism generating the synchronization of ENSO events to the annual cycle (Stein et al. 2014). Thus, below we will provide a brief description of the main theories that fall into this category.

One of the earliest suggestions about the tendency of ENSO seasonal synchronization was reported by Philander (1983), who suggested the seasonal movement of the Pacific intertropical convergence zone (ITCZ), and its effect on the atmospheric heating, (i.e. the coupled instability strength) as the responsible for ENSO's onset, hence for such seasonal synchronization. Furthermore, Hirst (1986) noted that other seasonal climatological factors that might enhance the coupled instability of the system are strong zonal wind in July-August, shallow thermocline in September-October, large zonal equatorial SST gradient in September, and high SST over the central equatorial Pacific in May. Subsequently, Battisti (1988) added to the previous list the influence of some weakening of oceanic upwelling in the central Pacific during March-May and some strengthening of the coastal upwelling in the eastern Pacific during August-September. Tziperman et al. (1997) found that the dominant factor in determining the strength of the ocean-atmosphere instability to be due to the seasonal wind convergence (i.e., the ITCZ location), while Yan and $\mathrm{Wu}$ (2007) work suggested that the seasonal change in the mean SST is the predominating factor. The results of Galanti et al. (2002) were partly consistent with those of Hirst (1986), suggesting that the seasonal oceanatmosphere coupling strength is influenced by the outcropping of the east Pacific thermocline during the second half of the year. Inter-basin teleconnections have also recently been implicated in the termination of ENSO events. As one example, some studies indicate that the basin warming of the tropical Indian Ocean is responsible for the weakening or reversal of equatorial westerly wind anomalies over the western Pacific at the mature phase of El Niño (Annamalai et al. 2005; Kug and Kang 2006; Obha and Ueda 2007, 2009; Yamanaka et al. 2009; Yoo et al. 2010). Finally, another mechanism, which involves meridional changes in the coupled ocean-atmosphere wind system and thought as a major negative feedback playing a role in the decay of El Niño events, will be emphasized below.
This paper focuses on the southward wind shift theory proposed by Harrison and Vecchi (1999) and Vecchi and Harrison (2003) as a major negative feedback involved in the phase synchronization between ENSO and the annual cycle. During El Niño events, the associated westerly wind anomalies are centred quite symmetric about the equator prior to the event peak (SON) whereas there is a shift of these anomalies towards south of the equator during the mature phase (DJF), with anomalous northerly winds developing north of the equator (Fig. 1). The magnitude of this southward wind shift appears to be dependent on the magnitude of the ENSO event, as suggested by Lengaigne et al. (2006). For instance, during DJF of strong El Niño events there is a strong southward movement along with movement towards east, with the maximum amplitude of the anomalous westerly winds shifting from date line in SON, to $160^{\circ} \mathrm{W}$ in DJF (Fig. 1 top). In contrast, during DJF of moderate El Niño events there is a much smaller southward wind shift, consistent with the findings of McGregor et al. (2013) who utilised multiple reanalysis products, and virtually no zonal movement of the anomalous westerlies (Fig. 1 middle). The zonal and meridional movement observed with easterly wind anomalies during La Niña events largely mirror for moderate El Niño events (Fig. 1 bottom), although with southerly winds developing north of the equator. These composite analyses shown in Fig. 1 are in broad agreement with those reported by Okumura and Deser (2010), where a different atmospheric reanalysis product was used.

This shift in wind anomalies has been studied by Harrison (1987), Harrison and Larkin (1998), Harrison and Vecchi (1999), Vecchi and Harrison (2003); and more recently it has been proposed to explain the seasonal synchronization since the resulting reduction of equatorial westerly wind anomalies has been shown to drive: (1) strong thermocline shoaling in the eastern equatorial Pacific (e.g., Harrison and Vecchi 1999; Vecchi and Harrison 2003, 2006; Lengaigne et al. 2006; Lengaigne and Vecchi 2009); (2) changes in equatorial warm water volume (WWV) (McGregor et al. 2012a, 2013) and (3) interhemispheric exchanges of upper ocean mass (McGregor et al. 2014). This shift has been linked to the southward displacement of the warmest SSTs and convection during DJF (Lengaigne et al. 2006; Vecchi 2006), and the associated minimal surface momentum damping of wind anomalies (McGregor et al. 2012a), both of which are due to the seasonal evolution of solar insolation. McGregor et al. (2013) also show that the discharging effect of the southward wind shift increases with increasing El Niño amplitude, while remaining relatively small regardless of La Niña amplitude. They suggest that this aspect may also help explain the ENSO phase duration asymmetry (i.e., why El Niño events have a shorter duration than La Niña events). 
Fig. 1 Composites of wind stress anomalies during strong El Niño events (top), moderateweak El Niño events (middle), and La Niña events (bottom). The anomalies are averaged from September to November during year 0 (left), and from December to February during year +1 (right). Shading indicates zonal components. Strong El Niño years: 1982/83 and 1997/98. Moderate-weak El Niño years: 1987/88, 1991/92, 1994/95, 2002/03, 2004/05, 2006/07 and 2009/10. La Niña years: $1984 / 85,1988 / 89$, 1995/96,1999/00, 2000/01, 2007/08, 2010/11 and 2011/12. See Sect. 2.1 for the ENSO definition
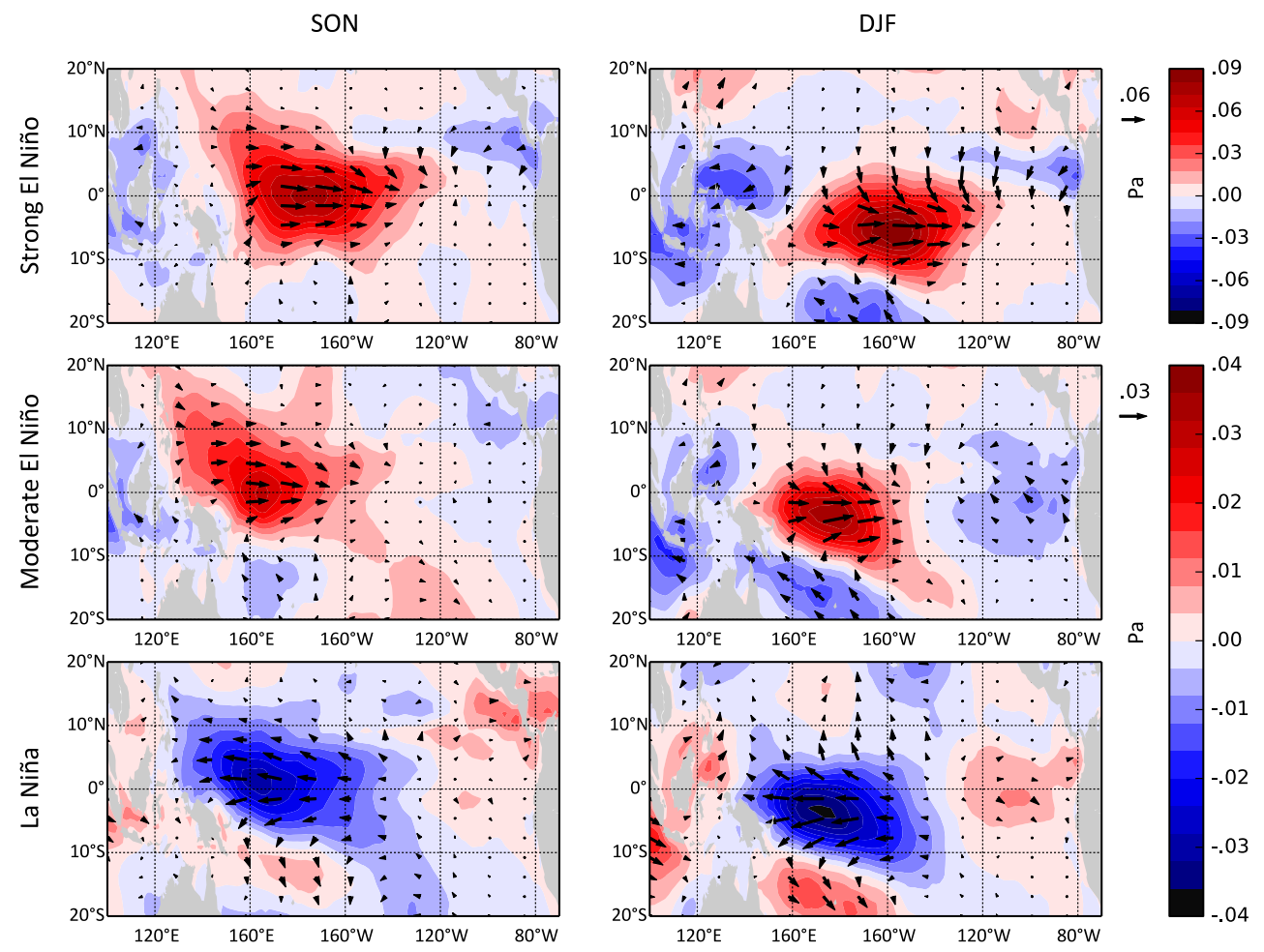

The purpose of this study is to single out the meridional wind movement of ENSO winds from the other possible mechanisms detailed above, and identify its role in the synchronization of ENSO events to the seasonal cycle. We also examine whether the ENSO phase asymmetry observed in this shift can account for the fact that La Niña events tend to persist for longer periods than El Niño (Okumura et al. 2011). Specifically, a simple hybrid coupled model (HCM), which utilises a statistical atmospheric that is able to function with and without the southward wind shift, is developed. We find that this meridional wind movement plays a crucial role in the seasonality of ENSO events since its inclusion in the model results in a moderate synchronization of modeled ENSO events to the seasonal cycle with maximum of SST anomalies (SSTA hereafter) in November-January. Additionally, we show that the duration of warm events is influenced by this shift, with the meridional wind movement favouring the early termination, while the duration of cool events appears to be marginally dependent on whether and how the shift is included in the model.

The rest of the paper is organized as follows. In the next section we shall present the SST dataset used and the two leading empirical orthogonal functions (EOFs) of wind stresses over the tropical Pacific, Sect. 3 describes the 3-component hybrid coupled model developed in this study. Sections 4 and 5 present our experiment results, with the large 1997/98 El Niño and 4-member ensemble of 100-year runs respectively, carried out with and without this southward wind shift and how sensitive the response of thermocline depth and, consequently, SSTA result. Finally, a discussion of the major findings is presented in Sect. 6.

\section{Data}

\subsection{SST data}

This study employs the monthly Niño-3.4 and Niño-3 indexes (namely SSTA averaged in the region $5^{\circ} \mathrm{S}-5^{\circ} \mathrm{N}$, $170^{\circ} \mathrm{W}-120^{\circ} \mathrm{W}$, and $5^{\circ} \mathrm{S}-5^{\circ} \mathrm{N}, 150^{\circ} \mathrm{W}-90^{\circ} \mathrm{W}$, respectively) derived from extended reconstructed SST (ERSST v3b) dataset (Smith et al. 2008) for the period 1979-2013 when wind stress data are required (Sects. 1 and 2) and for the period 1880-2013 when wind stresses are not required (Sect. 5). It is important to mention that the anomalies were computed with respect to a 1971-2000 monthly climatology. Here, we define an ENSO event when Niño3.4 index is either above $0.5^{\circ} \mathrm{C}$ (warm events) or below $-0.5{ }^{\circ} \mathrm{C}$ (cool events) for at least 5 consecutive months after a 3-month binomial filter applied, as in Deser and Coauthors (2012) to reduce month-to-month noise. Strong El Niño events are identified when their peak magnitudes are greater than $2.0{ }^{\circ} \mathrm{C}$, as Lengaigne et al. (2006). Further, this El Niño classification according to their magnitudes has been used in numerous other studies (e.g., Lengaigne and Vecchi 2009; Takahashi et al. 2011; Chen et al. 2015) 
It is also worth noting that the results of the southward wind shift during ENSO events are qualitatively similar if we instead differentiate between Eastern Pacific (EP) and Central Pacific (CP) type ENSO events rather than event magnitude, consistent with McGregor et al. (2013).

\subsection{Wind stress decomposition}

In order to determine the dominant patterns associated with interannual wind changes, an empirical orthogonal function (EOF) analysis of wind stresses over the tropical Pacific $\left(10^{\circ} \mathrm{S}-10^{\circ} \mathrm{N}\right.$ and $\left.100^{\circ} \mathrm{E}-70^{\circ} \mathrm{W}\right)$ is performed. Observational wind data is taken from the European Centre for Medium-Range Weather Forecasts (ECMWF) Interim Reanalysis (ERA-interim) (Dee and Uppala 2009). We first obtain the daily average wind data that span the period 1979-2013, the surface winds are then converted to wind stresses using the quadratic stress law (Wyrtki and Meyers 1976):

$\left(\tau_{x}, \tau_{y}\right)=C_{D} \rho_{a} W(U, V)$

where $U$ and $V$ are the zonal and meridional surface winds $\left(\mathrm{m} \mathrm{s}^{-1}\right)$ respectively; $W$ denotes the surface wind speed $\left(\mathrm{m} \mathrm{s}^{-1}\right), C_{D}=1.5 \times 10^{-3}$ is the dimensionless drag coefficient; and $\rho_{a}=1.2 \mathrm{~kg} \mathrm{~m}^{-3}$ represents the atmospheric density at the surface. The monthly mean wind stresses are calculated from the daily wind stresses and wind stress anomalies are computed by removing the monthly climatology of the entire 35-year of record.

As in previous studies (McGregor et al. 2012a, 2013; Stuecker et al. 2013), the global spatial patterns of the first two EOFs are obtained by regressing the associated principal component (PC) time series onto the anomalous wind stress at each spatial location. The first EOF (EOF1), which accounts for $33 \%$ of the equatorial region variance, features positive zonal wind anomalies in the western-central tropical Pacific (i.e., anomalous Walker circulation) that have their maximum amplitude south of the equator (Fig. 2a). It is clear that EOF1 represents ENSO variability since the correlation coefficient between this leading PC time series and SSTA averaged over the Niño-3 region $\left(5^{\circ} \mathrm{S}-5^{\circ} \mathrm{N}\right.$ and $\left.150^{\circ}-90^{\circ} \mathrm{W}\right)$ is 0.76 .

Regarding the second mode (EOF2), which explains 16 $\%$ of the equatorial region variance, the associated regression patterns are largely meridionally asymmetric featuring a prominent anticyclonic circulation in the western north Pacific region (Fig. 2b) consistent with the Philippine Anticyclone (e.g., Wang et al. 1999). Furthermore, EOF2 captures westerlies located south of the equator, around the same region as the maximum anomalies during DJF of El Niño events (Fig. 1 top). As it will be shown later in this section, this second mode is related to the southward wind shift, although as expected by the definition of the EOF

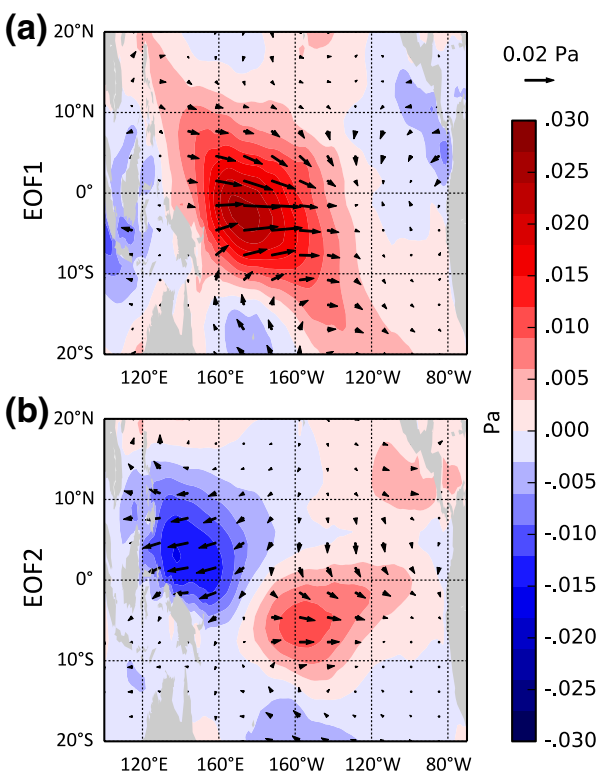

Fig. 2 The spatial pattern of surface wind stresses from a EOF1 and b and EOF2, which account for approximately 33 and $16 \%$ of the total variance over the tropical Pacific region, respectively. The shading contours represent the zonal components

analysis (e.g., Lorenz 1956), there is only a weak linear relationship $(\mathrm{r}=0.20)$ between the EOF2 time series (PC2) and ENSO (Niño-3 index). Interestingly however, PC2 has been linked to ENSO (McGregor et al. 2012a) as well as shown to play a prominent role in the recharge/discharge of equatorial region WWV (McGregor et al. 2013) and interhemispheric exchanges (McGregor et al. 2014).

Composites of PC1 around ENSO events reveal that event development occurs from $\mathrm{Mar}^{0}-\mathrm{May}^{0}$, and reaches the maximum amplitude near the end of the calendar year (Fig. 3). It is worthwhile to note the subtle differences between strong and moderate or weak El Niño events, where the maximum PC1 amplitudes in strong warm events tend to be stronger that seen during moderate events and zero values during moderate events are reached around 3 months before in strong events.

The composite of PC2 for warm events reveals a striking difference between the two types magnitudes of El Niño. For instance, PC2 during strong events changes sign dramatically around the mature phase (moderate negative prior and strong positive after), while PC2 values during moderate events tend to be negative prior to the mature phase and remain roughly zero thereafter (Fig. 3a). The evolution of PC2 during La Niña events is roughly mirrors that of moderate El Niño events, displaying positive values prior to event peak, which remain approximately zero thereafter (Fig. 3b).

These EOF results are consistent with the composites of wind stress anomalies shown in Fig. 1. For instance, PC1 

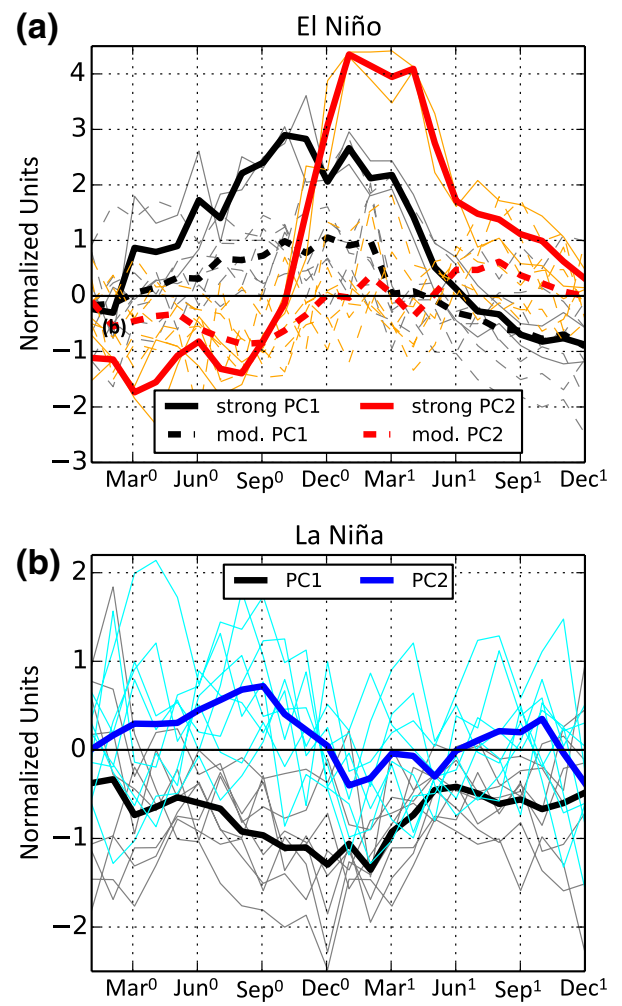

Fig. 3 Time series of the wind stresses PC1 and PC2 overlaid from $\mathrm{Jan}^{0}$ to $\mathrm{Dec}^{1}$ for a El Niño and $\mathbf{b}$ La Niña during 1979-2013. Each of the events is represented by an individual line, and the thick lines represent the mean values. Note the different scaling of the y-axes

(PC2) is positive (negative) during SON for El Niño events leading to westerly anomalies that are quasi-symmetric around the equator since the EOF2 anomalies of wind stress are positive over the Philippine region. If we analyse what occurs during DJF, we find that the maximum westerly anomalies in strong El Niño events are shifted southeastward towards the same area represented by the westerlies in the EOF2 pattern (Fig. 2b), consistent with the high positive values of PC2. During SON in both moderate El Niño and all La Niña events, PC1 and PC2 display anomalies of the same sign which ensures that the anomalies are largely symmetric about the equator, consistent with the observed composites (Fig. 1). The pattern observed for both moderate El Niño and all La Niña events during DJF (Fig. 1) is quite similar to EOF1 (Fig. 2a), which is in good agreement with PC2 values shown to be close to zero (Fig. 3). Therefore, in agreement with the previous studies of McGregor et al. (2012a, 2013) the combination of these two leading EOFs can be viewed to represent this southward shift of zonal wind stress anomalies during both El Niño and La Niña. It is worth emphasizing that McGregor et al. (2013) utilised eight global wind products, ERAinterim among others, finding a very similar spatial patterns and temporal variability for the two leading EOF modes amongst all data sets (see their Fig. S1 and Table S1).

\section{Coupled model description}

In this section, we describe the components of the hybrid coupled model which has been developed in this project with the objective of exploring the role of the southward wind shift in the synchronization of ENSO events to the seasonal cycle.

\subsection{Ocean model}

The ocean model utilised here is a shallow-water model (SWM), whose name refers to the fact that the horizontal scale of the planetary scale waves $(100-1000 \mathrm{~km})$ is much larger than the vertical scale (ocean depth $\sim 4 \mathrm{~km}$ ), which allows the Navier-Stokes equations to be simplified considerably. It is a linear reduced-gravity model resolved on a $1^{\circ}$ $\times 1^{\circ}$ spatial grid for the low- to mid-latitude global ocean between $57^{\circ} \mathrm{S}-57^{\circ} \mathrm{N}$ and $0^{\circ}-360^{\circ} \mathrm{E}$. The density structure of the $1 \frac{1}{2}$-layer baroclinic system consists of a well mixed active upper layer of uniform density overlaying a deep motionless lower layer of larger uniform density. These ocean density layers are separated by an interface (the pycnocline) that provides a good approximation of the thermocline. This is a crucial consequence as it allows us to quantify the upper-ocean heat content (e.g. Rebert et al. 1985), i.e., the warm-water volume (Meinen and McPhaden 2000), and provide an estimate of equatorial SSTA (e.g., Kleeman 1993; Zelle et al. 2004).

The ocean dynamics are described by the linear reducedgravity form of the shallow-water equations detailed below [Eqs. (2)-(4)]:

$u_{t}-f v+g^{\prime} \eta_{x}=\frac{\tau^{x}}{\rho H}+F_{m}$

$v_{t}+f u+g^{\prime} \eta_{y}=\frac{\tau^{y}}{\rho H}+F_{m}$

$g^{\prime} \eta_{t}+c_{1}^{2}\left(u_{x}+v_{y}\right)=0$

where $u$ and $v$ are the eastward and northward components of velocity respectively $\left(\mathrm{m} \mathrm{s}^{-1}\right), t$ is time (s), $H$ represents the mean pycnocline depth, $H=300 \mathrm{~m}$ (Tomczak and Godfrey 1994, p. 37), $f\left(\mathrm{~s}^{-1}\right)$ is the Coriolis parameter, $\rho$ is the ocean water density, $\rho=1000 \mathrm{~kg} \mathrm{~m}^{-3}$, and $F_{m}$ the bottom friction per unit mass. The reduced gravity, $g^{\prime}$, reflects the density difference between the upper and lower layers. We use the typical value of $g^{\prime}=0.026 \mathrm{~m} \mathrm{~s}^{-2}$ (Tomczak and Godfrey 1994, p. 37). The corresponding first baroclinic mode gravity wave speed, $\left.c_{1}=\sqrt{g^{\prime} H}\right)$, is $2.8 \mathrm{~m} \mathrm{~s}^{-1}$. The 
long Rossby wave speed $C_{R}\left(\mathrm{~m} \mathrm{~s}^{-1}\right)$ is given by the equation, $C_{R}=\beta\left(c_{1}^{2} / f^{2}\right)$, where $\beta\left(\mathrm{m}^{-1} \mathrm{~s}^{-1}\right)$ is the derivative of $f$ northward.

The model time step is $2 \mathrm{~h}$ and Fischer's (1965) numerical scheme is utilized for model time stepping. Motion in the upper layer is driven by the applied wind stresses (per unit density), $\tau\left(\mathrm{m}^{2} \mathrm{~s}^{-2}\right.$ ), which are anomalies from longterm monthly means (i.e., seasonal cycle removed). The associated response of the ocean is displayed by the vertical displacement of the thermocline, $\eta(\mathrm{m})$, and the horizontal velocity components ( $u$ and $v$ ) of the flow velocity. This model formulation permits Ekman pumping and both Rossby and Kelvin wave propagation along the thermocline to be generated with appropriate large-scale wind stress forcing. It also includes realistic continental boundaries that were calculated as the location where the bathymetric dataset of Smith and Sandwell (1997) has a depth of less than the model mean thermocline depth of $300 \mathrm{~m}$.

Regarding the calculation eastern-central Pacific SSTA, we utilise a simplified version Kleeman's (1993) SST equation by applying the thermocline anomaly term only. Kleeman (1993) shows that this single term is primarily responsible for hindcast skill in ENSO predictions. Thus, while being the simplest scheme, it contains the essential physics required to produce realistic SSTA. Hence, the equatorial SSTA depends only on the thermocline depth anomaly. Changes in the SSTA on the equator are modeled by the equation

$T_{t}=\alpha(x) \eta(x)-\epsilon T$

where $T$ is the SSTA at time $t, \epsilon$ is the Newtonian cooling coefficient, $\epsilon=2.72 \times 10^{-7} \mathrm{~s}^{-1}, x$ is the longitude and $\alpha$ is a longitude-dependent parameter that relates the modeled oceanic thermocline depth displacement $\eta$ along the equator to the SSTA, being $\alpha=3.4 \times 10^{-8}{ }^{\circ} \mathrm{C} \mathrm{m}^{-1} \mathrm{~s}^{-1}$ in the eastern Pacific and reducing linearly west of $140^{\circ} \mathrm{W}$ to a minimum of $\alpha / 5$ at the western equatorial boundary at $120^{\circ} \mathrm{E}$. Such a difference reflects the fact that the equatorial thermocline depth anomalies display a tighter connection with SSTA in the east than the west (Zelle et al. 2004). For the rest of latitudes, a fixed meridional structure that decays away from the equator with an $e$-folding radius of $10^{\circ}$ is assumed. Taking into account the non-linear relationship between central Pacific zonal wind stress anomalies and Niño-3 index as reported by Frauen and Dommenget (2010), the parameter $\alpha$ is reduced by $20 \%$ for negative SSTA in Niño-3 region. In addition, a threshold of $37.5 \mathrm{~m}$ is set on the maximum absolute depth of equatorial thermocline anomalies in order to prevent runaway coupled instability.

It is also worthwhile to mention that the use of this simplified SST equation implies that each of these HCMs can generate only EP El Niño and La Niña events, i.e. only one
EOF of SSTA. Therefore, the results of these HCM simulations will not distinguish between EP-CP event differences. It has been documented in several studies that this ocean model can produce observed variations of ocean heat content and sea surface heights reasonably well (e.g., McGregor et al. 2012a, b). Furthermore, a validation of this ocean model was carried out by simply forcing the model with ERA-interim monthly wind stress anomalies over 1979-2013. The modeled Niño-3 and Niño-3.4 indexes were then compared with those observed during the same period revealing correlation coefficients of 0.83 and 0.82 , respectively (statistically significant above the $99 \%$ level).

\subsection{Statistical atmospheric model}

The statistical atmosphere has been constructed by the two leading EOFs of wind stresses over the tropical Pacific. It has been shown above that the linear combination of both EOFs can reproduce quite well the southward shift of the maximum westerly wind anomalies and its related seasonal weakening of equatorial westerly wind anomalies, both of which have been proposed to contribute to the transition between El Niño and La Niña (e.g., Harrison and Vecchi 1999; Vecchi and Harrison 2003, 2006; Lengaigne et al. 2006; McGregor et al. 2012a, 2013).

The statistical atmospheric model is coupled to the ocean SWM to produce three hybrid coupled models (HCM): HCM1 consists of EOF1 only (i.e., no meridional wind movement); HCM1+2 and $\mathrm{HCM} 1+2 \mathrm{~S}$ include both EOF1 and EOF2 (i.e., they both produce meridional wind movement). In all cases, the EOF1 coupling is achieved by modelling the EOF1 surface wind stress response by:

$\left(\tau_{1}^{x}, \tau_{1}^{y}\right)=P C 1(t) \times\left(E O F 1^{x}, E O F 1^{y}\right)$

where $P C 1$ is approximated by the modeled Niño-3 index. The close relationship between these two variables was noted earlier.

The method used to calculate PC2 in HCM1+2 is a least squares second-order polynomial fit from PC1 for each calendar month (month),

$\left(\tau_{2}^{x}, \tau_{2}^{y}\right)=P C 2(P C 1$, month $) \times\left(E O F 2^{x}, E O F 2^{y}\right)$

where we use the two closest months to our month of interest (e.g., data taken for February, includes January and March also) in order to obtain a smooth transition of PC2 values from one month to another (Fig. 4). The seconddegree polynomial function is of the form,

$P C 2=a \cdot P C 1^{2}+b \cdot P C 1$

where $a$ and $b$ depend on calendar month. The small independent term is set to zero in order to remove any seasonal cycle in EOF2. A full list of quadratic polynomial 


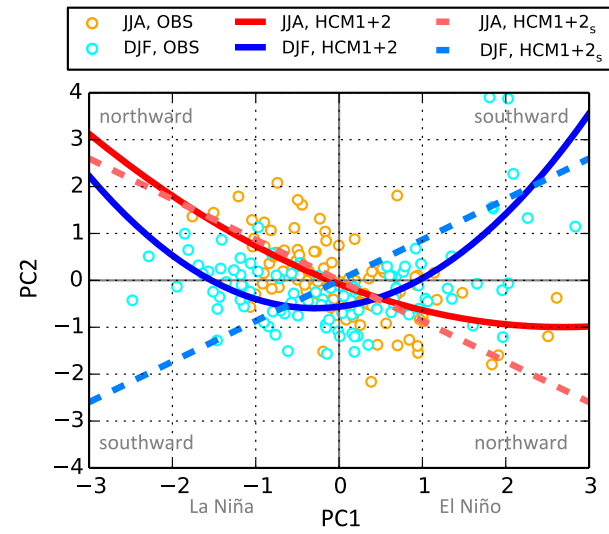

Fig. 4 Scatterplot of the wind stress PC2 against PC1 based on the observations (1979-2013) for two 3-month periods: June-August (orange dots); and December-February (light blue dots). The underlying solid (dashed) lines represent the regression used in $\mathrm{HCM} 1+2$ $(\mathrm{HCM} 1+2 \mathrm{~S})$. See text for the description of the two hybrid coupled model represented in this panel. The directions indicated on the corners in gray mark the direction of the meridional movement of ENSO wind anomalies

coefficients as well as their correlation coefficients and RMSE for each calendar month are given in Table 1.

The method used to calculate PC2 in HCM1+2s, on the other hand, is based on a climate mode that emerges through the atmospheric non-linear interaction between ENSO and the annual cycle known as C-mode (Stuecker et al. 2013, 2015). Here PC2 wind stresses are calculated by,

$\left(\tau_{2}^{x}, \tau_{2}^{y}\right)=P C 2_{S} \times\left(E O F 2^{x}, E O F 2^{y}\right)$

where $P C 2_{S}=P C 1(t) \times \cos \left(\omega_{a}\right.$ month $\left.-\varphi\right)$ refers to PC2 simple, which comes from the lowest-order term of the atmospheric nonlinearity. Here $\omega_{a}$ denotes the angular frequency of the annual cycle, $\omega_{a}=2 \pi / 12 \mathrm{rad}^{\mathrm{month}}{ }^{-1}$ and $\varphi$ represents a one-month phase shift, $\varphi=2 \pi / 12 \mathrm{rad}$. How well observed data fit this HCM for each calendar month is indicated by RMSE and correlation coefficients in Table 1 .
It is clear that the relationship between PC1 and PC2 values depends strongly on calendar month (Fig. 4). The relationship between the pair is quasi-linear during JJA, with increasing values of $\mathrm{PC} 1$ being related to decreasing values of PC2. The relationship during DJF, on the other hand, displays a clear non-linearity with $\mathrm{PC} 2$ values increasing for increasing positive values of PC1, while the PC2 amplitude also appears to increase for decreasing negative values of PC1. Thus, the seasonal difference between the relationship between $\mathrm{PC} 1$ and $\mathrm{PC} 2$ is most pronounced for strong El Niño events (high values of PC1). Such behaviour is represented reasonably well by the $\mathrm{HCM} 1+2$ configuration (Fig. 4); for instance, for strong El Niño events $(2<\mathrm{PC} 1<3)$, PC2 prior to the event peak (JJA) has values around minus unity, while around the event peak (DJF) PC2 is between two and three, which is consistent with the sign change shown in Fig. 3a. Interestingly, however, such a strong seasonal change is not observed in moderate El Niño events (PC1 1) and La Niña events $(\mathrm{PC} 1<0)$, which is consistent with the ENSO phase and type asymmetry reported by Lengaigne et al. (2006). This ENSO phase and type non-linearity is not represented, however, in $\mathrm{HCM} 1+2 \mathrm{~S}$ where the relationship between PC2 and PC1 is linear regardless the calendar month (Fig. 4). Thus, the HCM1+2 simulations only have a weak southward wind shift during La Niña events, while the HCM1+2s simulations have a strong southward wind shift and the magnitude of the easterlies are also stronger.

Reconstructing PC2 with the polynomial fit of HCM1+2 and comparing with $\mathrm{PC} 2$ from the observations reveals a correlation coefficient of 0.61 , while doing the same analysis for the $\mathrm{HCM} 1+2 \mathrm{~S}$ reconstructed PC2, reveals a correlation coefficient of 0.42 . Thus, here we consider HCM1+2 as the more realistic experimental set up and $\mathrm{HCM} 1+2 \mathrm{~S}$ as the idealized southward wind shift, with RMSE 0.66 and 0.70 in JJA; and 0.83 and 1.20 in DJF, respectively (see Table 1 for the rest of calendar months). However, due to lack of data for strong negative SSTA over the eastern

Table 1 Polynomial parameters of $P C 2=a \cdot P C 1^{2}+b \cdot P C 1$ used in HCM1+2 simulations for each calendar month as well as correlation coefficient and root mean squared error (RMSE) of HCM1+2 and $\mathrm{HCM} 1+2 \mathrm{~S}$

\begin{tabular}{|c|c|c|c|c|c|c|c|c|c|c|c|c|}
\hline Parameter & Jan & Feb & Mar & Apr & May & Jun & Jul & Aug & Sep & Oct & Nov & Dec \\
\hline a & 0.38 & 0.46 & 0.49 & 0.53 & 0.30 & 0.13 & 0.13 & 0.09 & 0.14 & 0.18 & 0.17 & 0.27 \\
\hline $\mathrm{b}$ & 0.22 & 0.17 & 0.11 & -0.06 & -0.19 & -0.47 & -0.68 & -0.70 & -0.62 & -0.48 & -0.20 & 0.03 \\
\hline $\mathrm{r}(\mathrm{HCM} 1+2)$ & 0.70 & 0.71 & 0.58 & 0.46 & 0.24 & 0.36 & 0.61 & 0.69 & 0.71 & 0.61 & 0.40 & 0.56 \\
\hline RMSE(HCM1+2) & 0.83 & 0.89 & 1.05 & 1.05 & 0.98 & 0.79 & 0.66 & 0.61 & 0.56 & 0.61 & 0.77 & 0.85 \\
\hline $\mathrm{r}\left(\mathrm{HCM} 1+2_{\mathrm{S}}\right)$ & 0.42 & 0.45 & 0.33 & 0.18 & -0.01 & 0.34 & 0.59 & 0.68 & 0.66 & 0.47 & 0.14 & 0.24 \\
\hline $\mathrm{RMSE}\left(\mathrm{HCM} 1+2_{\mathrm{S}}\right)$ & 1.20 & 1.27 & 1.30 & 1.18 & 1.00 & 0.80 & 0.70 & 0.69 & 0.69 & 0.71 & 0.84 & 1.05 \\
\hline
\end{tabular}

Note that the highest (lowest) values of RMSE are obtained around March (September) in both simulations, with differences roughly $30 \%$ between HCM1+2 and HCM1+2S during January-February, being the former with lower values for all calendar months, although no significant difference is seen between the two HCMs during May-August. However, the strongest (weakest) relationship between PC2 and PC1 are obtained during boreal winter and summer (spring and autumn) for both HCMs 
equatorial Pacific for our analysis period, we take both methods into consideration in order to examine the sensitivity of the HCM results.

\subsection{Westerly wind burst model}

Westerly wind activity has been shown to play an important role in the onset of El Niño events (Latif et al. 1988; Kerr 1999; Lengaigne et al. 2004; McPhaden 2004). These wind events, known as westerly wind bursts (WWB), force downwelling Kelvin waves, which propagate to the eastern equatorial Pacific and ultimately act to warm SST there, potentially initiating the event (e.g., Giese and Harrison 1990, 1991). Equatorial westerly wind activity has been associated with tropical cyclones (Keen 1982), cold surges from midlatitudes (Chu 1988), the convectively active phase of the Madden-Julian oscillation (Chen et al. 1996; Zhang 1996), or a combination of all three (Yu and Rienecker 1998).

Although different definitions have been proposed to diagnose WWB from observations (e.g., Harrison and Vecchi 1997; Yu et al. 2003; Eisenman et al. 2005), there is a broad agreement that it can be represented roughly by a Gaussian shape in both space and time,

$u_{\mathrm{wwb}}(x, y, t)=\operatorname{Aexp}\left(-\frac{\left(t-T_{0}\right)^{2}}{T^{2}}-\frac{\left(x-x_{0}\right)^{2}}{L_{x}^{2}}-\frac{\left(y-y_{0}\right)^{2}}{L_{y}^{2}}\right)$

where $x_{0}\left(160^{\circ}\right)$ and $y_{0}\left(0^{\circ}\right)$ are the central longitude and latitude of the wind event, $T_{0}$ (10 days) is the time of peak wind, $A$ is the peak wind speed, T (10 days) represents the event duration, and $L_{x}\left(20^{\circ}\right)$ and $L_{y}\left(9^{\circ}\right)$ are the spatial scales. The values of these parameters are set here to obtain realistic values of wind stresses over the western Pacific (Niño-4 region). In regards to their frequency, Eisenman et al. (2005) found and average of 3.1 westerly wind events (WWEs) per year during 1990-2004, Gebbie et al. (2007) identified an average of 3.6 WWEs per year during 19792002 and Verbickas (1998) found 3.8 WWEs per year during 1979-1997.

In Sect. 5 we incorporate WWB into the HCM by utilising the WWB equation above, and having the probability of a WWB beginning on any given day set a fixed parameter which depends on the simulation set up. This means that we have WWBs that are purely stochastic, with the different parameter choice simply modulating the rate of WWB occurrence and their magnitude. Although it has been increasingly recognized that WWB are partially modulated by the SST field and partially dependent upon stochastic processes in the atmosphere (e.g., Kessler and Kleeman 2000; Eisenman et al. 2005; Gebbie et al. 2007), here WWB are represented by purely stochastic way due to the simplicity of our SSTA formulation (Gebbie and Tziperman 2009). Nevertheless, this paper is not about the response of El Niño events to different flavours of WWB. Rather, the intent of this paper is to focus on the role of the southward wind shift on the termination of ENSO events.

\section{Response of the hybrid coupled models to observed WWBs}

This first experiment is initiated by forcing all three hybrid coupled model versions with ERA-interim wind stress anomalies during the 16-month period (January 1996-April 1997). These are the anomalous wind stresses prior to the 1997/98 extreme El Niño, that contain numerous WWBs thought to initiate the event (McPhaden 1999). Each models statistical atmosphere and WWB components are inactive during this initial forcing period, and after this forcing period only the statistical atmospheric component is activated. Each of these simulations is then run for ten years after coupling, although SSTA in Niño-3 region are only plotted until December 2000 in Fig. 5 because the remaining evolution lacks importance.

Visual analysis of the model SSTA reveals, (1) that in its current configuration all three model versions are in a damped oscillatory state, and (2) that all three model versions do a reasonable job reproducing the 1997/98 El Niño peak. This last point is not noted to suggest predictive skill; it is the difference between each of these three model configurations that is of interest. First of all, the El Niño peak magnitudes in $\mathrm{HCM} 1+2$ and $\mathrm{HCM} 1+2_{\mathrm{S}}$ are stronger than in HCM1. Secondly, normal values (i.e. SSTA $=0{ }^{\circ} \mathrm{C}$ ) after the warm event are reached up to 3 months earlier in HCM1+2 compared to HCM1 and HCM1+2s. This suggests that the addition of EOF2 in $\mathrm{HCM} 1+2$ allows $\mathrm{El}$ Niño events to terminate more abruptly, while it also makes

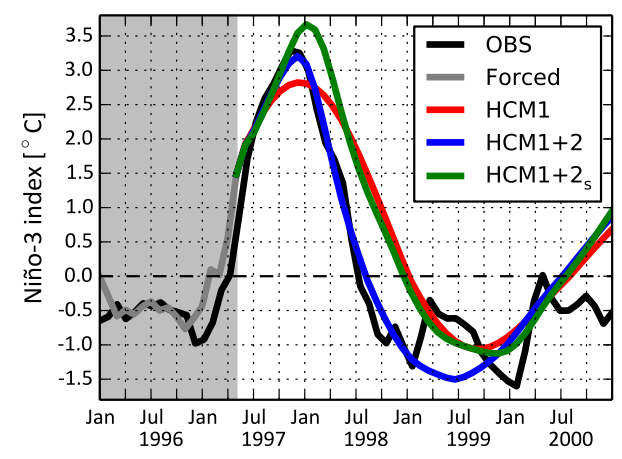

Fig. 5 Time series of SSTA in Niño-3 region for the period 19962000 in observations (black line), forced run (gray line) with wind stress anomalies observed during 16-month period, and coupled runs to $\mathrm{HCM} 1$ (red line), $\mathrm{HCM} 1+2$ (blue line), and $\mathrm{HCM} 1+2 \mathrm{~S}$ (green line) 
the HCM1+2 temperature evolution more consistent with that observed (Fig. 5). Due to the huge growth of the event in $\mathrm{HCM} 1+2 \mathrm{~S}$, its effective termination occurs at similar time to HCM1 although the rate change of the SSTA of $\mathrm{HCM} 1+2 \mathrm{~S}$ is as strong as that seen in $\mathrm{HCM} 1+2$.

Such differences among the three HCM time series are due to the fact that the both magnitude and spatial distribution of zonal wind stresses are distinct. Figure 6 displays contour maps of zonal wind stress anomalies during ASO of 1997 (left column) and FMA of 1998 (right column) for the observations and the three HCM simulations. The magnitudes of western equatorial Pacific westerlies during the growth phase (ASO) in simulations with EOF2 $(\mathrm{HCM} 1+2$ and $\mathrm{HCM} 1+2 \mathrm{~S})$ are stronger than in that with EOF1 only (Fig. 6), and consistent with expectations the subsequent eastern equatorial Pacific warming is stronger (e.g., Vecchi and Harrison 2000). After the mature of phase of the large 1997/98 El Niño, however, the maximum peaks of westerlies in $\mathrm{HCM} 1+2$ and $\mathrm{HCM} 1+2_{\mathrm{S}}$ are moved to central Pacific as observed (Fig. 6) and more importantly shifted south of the equator $\left(\sim 5^{\circ} \mathrm{S}\right)$. It is worth highlighting that the southward wind shift that occurs within this period is linearly related to the NDJ discharge of heat content (McGregor et al. 2013). Thus, the HCM1+2 and $\mathrm{HCM} 1+2_{\mathrm{S}}$ simulations are expected to discharge equatorial heat content much faster than HCM1, which has a fixed structure, ultimately leading to the more abrupt termination of the El Niño event, as shown here.

\subsection{Perpetual month experiments}

Previous literature (e.g., Zebiak and Cane 1987) has suggested that the seasonal changes of the Pacific's background state may be considered as a seasonal modulation of the coupling strength between the ocean and the atmosphere. Here, we will not be considering the changes in background state explicitly, rather we will be considering changes in the surface wind response to ENSO (the southward wind shift) which can be deemed a product of the background state changes (e.g., Vecchi and Harrison 2006; McGregor et al. 2012a). Thus, in order to further examine the variability of the background stability in each calendar month, we have run a series of 12 perpetual month experiments with $\mathrm{HCM} 1+2$, in which the relationship between PC1 and PC2 was fixed to a given calendar month (i.e., $\mathrm{PC} 2$ is a function of PC1 only, while the coefficients which would vary with month are fixed to the prescribed month regardless the current calendar month of the simulations). Each of these 12 experiments (one for each calendar month) are initiated by forcing with wind stress anomalies observed from ERAinterim during a 16-month period (January 1996-April 1997). As above, each models statistical atmosphere and WWB components are inactive during this initial forcing period, and after this forcing period only the statistical atmospheric component is activated.

Here, as in Tziperman et al. (1997), we think of the amplitude of the resulting El Niño event as a rough measure of the coupling strength, or stability or the background state where a higher amplitude El Niño indicates more unstable background state or stronger coupling strength. In Fig. 7a we present the Niño-3 index and WWV anomaly, where WWV is defined as the volume of water above the thermocline between $5^{\circ} \mathrm{S}-5^{\circ} \mathrm{N}$ and $120^{\circ} \mathrm{E}-80^{\circ} \mathrm{W}$, from the two most extreme calendar months (January and July) of HCM1+2. It is noted that January has the weakest
Fig. 6 Zonal surface wind stress anomalies $(\mathrm{Pa})$ during ASO in 1997 (left) and FMA in 1998 (right) from observations (top panels), HCM1 (second line), $\mathrm{HCM} 1+2$ (third line) and $\mathrm{HCM} 1+2_{\mathrm{S}}$ (bottom panels)
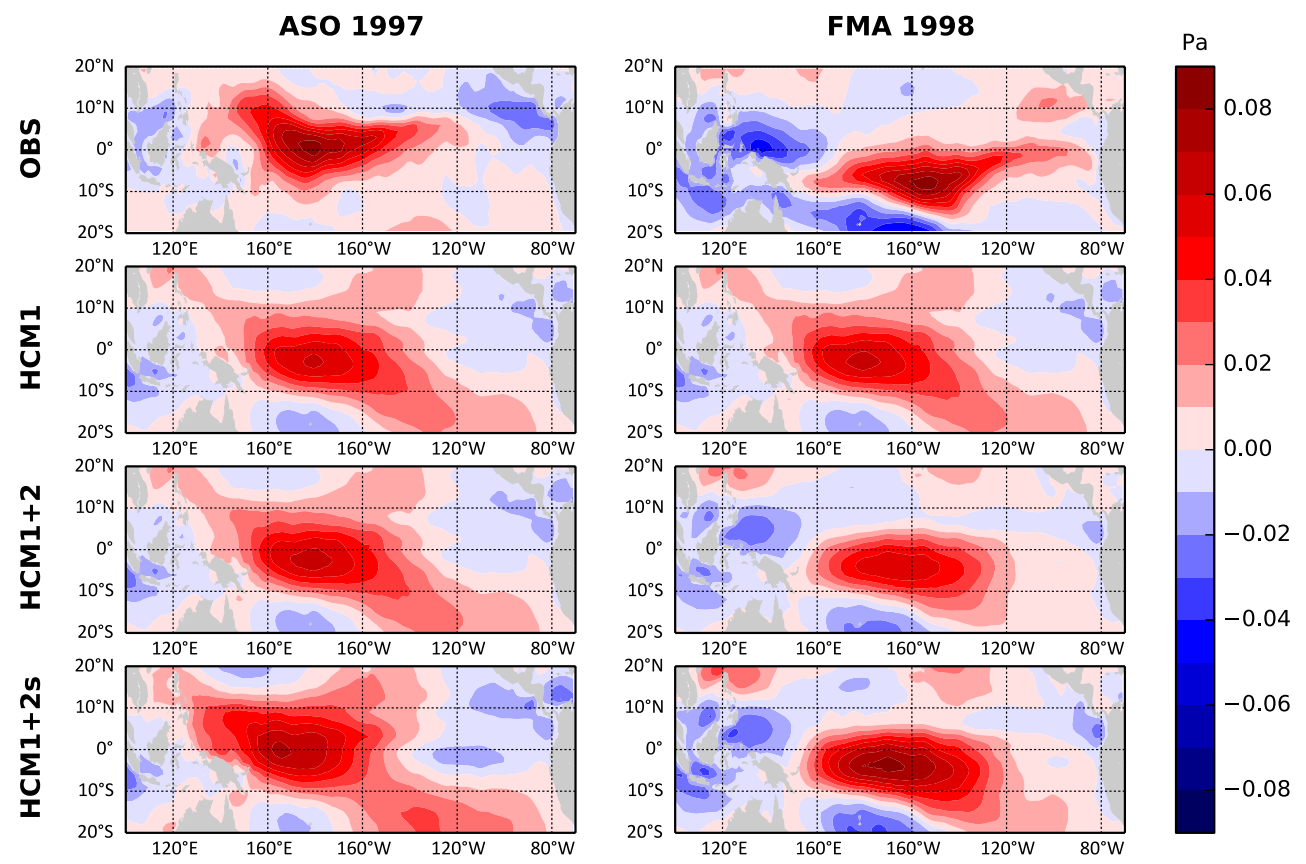

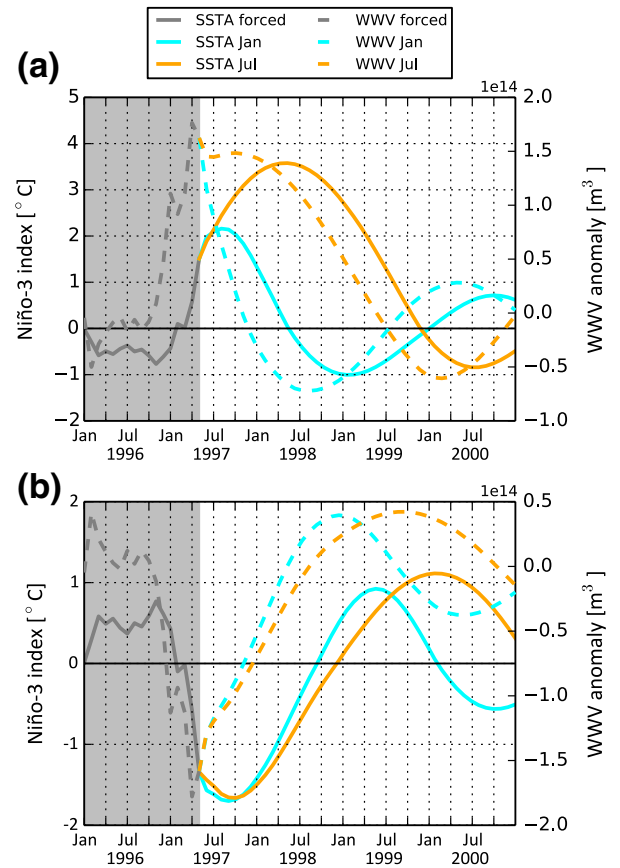

Fig. 7 a Time series of the SSTA in Niño-3 region (solid lines) and warm water volume anomalies integrated over $5^{\circ} \mathrm{S}-5^{\circ} \mathrm{N}$ and $120^{\circ} \mathrm{E}-80^{\circ} \mathrm{W}$ (dashed lines) for the period 1996-2000 in forced run (gray lines) with wind stress anomalies observed during the first 16 months and then coupled to HCM1+2 fixing the configuration of EOF2 at two calendar months, January (light blue) and July (orange). b The same as a but multiplying the wind stress anomalies during the forced period by minus one

ocean-atmosphere coupling (most stable conditions) and July has the strongest ocean-atmosphere coupling (most unstable conditions) (Fig. 7a). As a consequence, the duration of the resulting El Niño event in $\mathrm{HCM} 1+2$ is much longer when EOF2 is fixed in July ( $\sim 2.5$ years) than in January ( $\sim 1$ year) (Fig. $7 \mathrm{a})$. It is also interesting to note that upon coupling, the perpetual January HCM1+2 simulation instantaneously begins to discharge WWV, while the perpetual July HCM1+2 simulation after a brief initial adjustment maintains WWV for a further 6-9 months.

These changes in coupling strength are consistent with PC2 and PC1 values in January and July shown in Fig. 4, where ENSO's winds (reconstructed with EOF1 and EOF2) are largely symmetric about the equator in July and display a strong asymmetry (southward shift) in January. Further to this, the SSTA and WWV changes displayed are consistent with our expectations based on previous studies, whereby the southward wind shift acts to enhance the discharge WWV (e.g., McGregor et al. 2014), which is shown to set up conditions favourable for the termination of ENSO warm events (Jin 1997; Meinen and McPhaden 2000).

As a demonstration of the ENSO phase non-linearity of HCM1+2 we repeated the above perpetual month experiments, however, this time simply multiplying the zonal winds forcing by minus one. Using the amplitude of the resulting La Niña event as a rough measure of the coupling strength, we find virtually no difference between the perpetual January and July experiments in SSTA or WWV (Fig. 7b). It is also interesting to note that the absolute value of SSTA does not get as large for La Niña events as it does for El Niño events, which is a reflection of the differing relationship between thermocline depth and SST reported in Sect. 3.1.

\subsection{Seasonal synchronization}

Previous studies (e.g., Harrison and Vecchi 1999; McGregor et al. 2012a) and the results above suggest that the southward wind should play a prominent role in the synchronization of ENSO events to the seasonal cycle. The goal of this set of experiments is to demonstrate, in an idealised setting, the southward wind shift role in the DJF event peak and, hence, the synchronization of ENSO events to the seasonal cycle.

To this end, four experiments are conducted, all of which are initiated by forcing with wind stress anomalies observed from ERA-interim during the 16-month period between January 1996 and April 1997. As above, each models statistical atmosphere and WWB components are inactive during this initial forcing period, and after this forcing period only the statistical atmospheric component is activated. What differs between each of the experiments, however, is the calendar month each of the two HCMs (HCM1 and HCM1+2) is initialised in when activated. The four runs for each HCM are initiated in February, May, August and November. Also, unlike in the perpetual month experiments, the calendar month is not held fixed at the initialization month, meaning

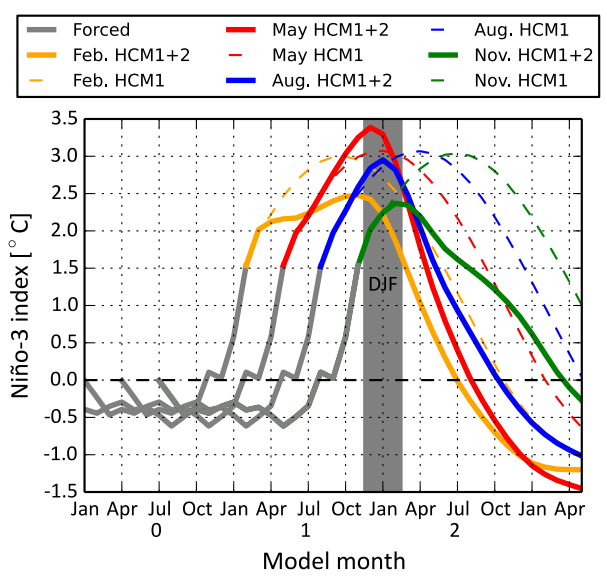

Fig. 8 Time series of the SSTA in Niño-3 region forcing the model during a 16-month period (gray lines) and then coupled to HCM1+2 (solid lines) and HCM1 (dashed lines) by starting in different calendar months: February (orange), May (red), August (blue) and November (green) 
that the month does evolve with time after initialisation. This basically acts as a shift in timing of the applied wind stress forcing, which is representative of El Niño event triggering WWBs occurring at different times of the year.

Figure 8 depicts the Niño-3 index time series for the experiment described above. As expected for HCM1, each simulation produces a similar pattern for all runs with the maximum SSTA being reached roughly 7 months after coupling and termination occurring roughly 12 months after that (Fig. 8). As the coupling shifts to later in the calendar year in the HCM1+2 simulations, however, the wind stresses become less symmetric about the equator, thus the maximum amplitude of the events gets smaller. The most significant feature, however, is that each of the simulations reach their SSTA peak during DJF regardless the calendar month when the model coupling is initiated. Thus, this set of experiments demonstrates that the monthly varying coupling strength produced by the southward wind shift acts to synchronize the modeled ENSO event to the seasonal cycle.

\section{Response of the hybrid coupled models to stochastic WWBs}

In this section, we conduct a 4-member ensemble of 100year simulations utilising: (1) four amplitudes of WWB $\left(8,10,12\right.$ and $\left.14 \mathrm{~m} \mathrm{~s}^{-1}\right)$, (2) three probabilities of occur-

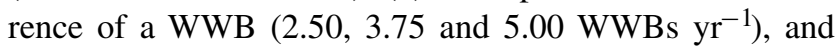
(3) for each of the three HCM (HCM1, HCM1+2 and HCM1+2s), giving 144 ensemble simulations. Each of the four ensemble members for each choice of WWB amplitude, occurrence probability and HCM version differ only in the set of random numbers used to set the timing of occurrence of the WWBs.

\subsection{Seasonal synchronization}

Here we aim too more fully understand the role of the EOF2 (i.e. the southward wind shift during El Niño events) in the synchronization of ENSO to the seasonal cycle. The tendency of seasonal synchronization of ENSO events can be seen in the observations, after normalization of Niño-3 index time series, in maximum peak $\left(1.3^{\circ} \mathrm{C}\right)$ in the standard deviation in December and minimum $\left(0.75{ }^{\circ} \mathrm{C}\right)$ in April (Fig. 9). Thus, we present the standard deviation of the SSTA in the central-eastern Pacific (Niño-3 region) for each calendar month and for all runs of the ensemble (Fig. 9).

All HCM1 simulations, i.e. without EOF2, have standard deviations that are roughly constant throughout the year. That is, they do not show any synchronization to the annual cycle. The simulations including EOF2, on the other hand, do exhibit seasonal preference in the standard deviation, although there are some differences when compared to

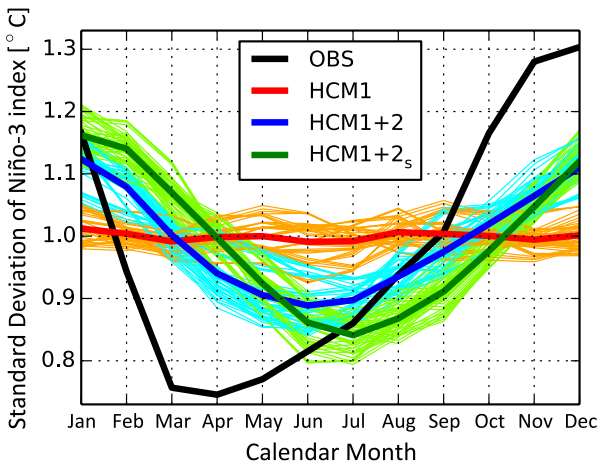

Fig. 9 Monthly standard deviation of Niño-3 SSTA from observations (black line), and all simulations: HCM1 (red), HCM1+2 (blue) and $\mathrm{HCM} 1+2 \mathrm{~S}$ (green). Thin lines represent individual simulations and thick lines indicate the mean of each HCM

that observed. For instance, the HCM1+2 ensemble mean features a boreal winter maximum $\left(1.1^{\circ} \mathrm{C}\right)$ standard deviation and a boreal summer minimum $\left(0.9^{\circ} \mathrm{C}\right)$. Comparing this with observations reveals that the model displays a smaller range, and that the maximum lags that observed by approximately 1 month, while the minimum in June lags that observed by 2 months (Fig. 9). The HCM1+2s ensemble mean displays a boreal winter (January) maximum of $1.2{ }^{\circ} \mathrm{C}$, which lags that observed by one month, and a boreal summer minimum $\left(0.85{ }^{\circ} \mathrm{C}\right)$ that lags by 3 months as that observed, and again exhibiting a weaker range of variability (Fig. 9). Therefore, the correlation coefficient between HCM1 +2 and observations is higher $(r=0.73)$ than that between HCM1+2S and observations $(r=0.45)$.

To characterize the seasonality of the standard deviation throughout the year, here we use the correlation coefficient between the modeled and observed monthly standard deviation of Niño-3 index, defined as phase-locking performance index (PP) by Ham and Kug (2014), as well as the ratio of the maximum and minimum modeled monthly standard deviation. These two parameters in addition to the standard deviation of SSTA in Niño-3 region are plotted in Fig. 10 as a function of the magnitude and probability of WWB.

As expected, the standard deviation increases for both magnitude and number of WWE per year higher for all simulations (Fig. 10a-c). However, it is noteworthy that the standard deviations in HCM1 simulations are slightly higher than the others for the same magnitude and probability values as a result of longer duration of warm events, as we shall present in Sect. 5.3. On average, the observed standard deviation $\left(0.84{ }^{\circ} \mathrm{C}\right.$ for the period $1880-2013$ and $0.87^{\circ} \mathrm{C}$ for the period 1979-2013) falls in the bottom left hand corner of the modeled standard deviations (Fig. 10a-c).

The PP indices in the HCM1 ensemble are roughly 0 regardless of the WWB parameters (Fig. 10d). The $\mathrm{HCM} 1+2$ and $\mathrm{HCM} 1+2_{\mathrm{S}}$ correlation coefficients, 
(a)

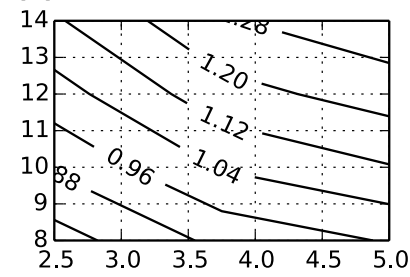

(d)

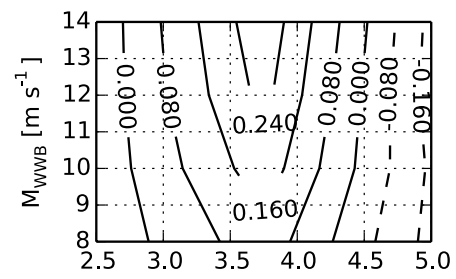

(g)

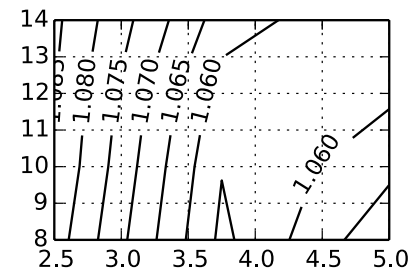

(b)

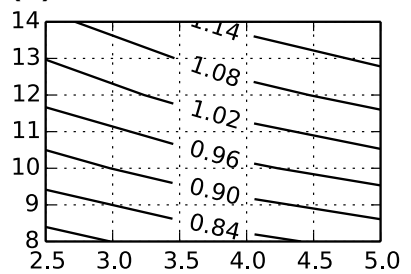

(e)

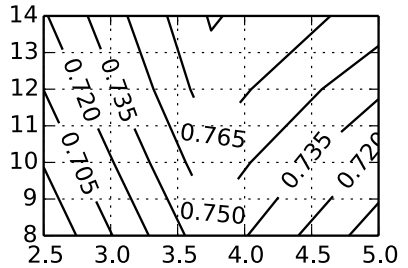

(h)

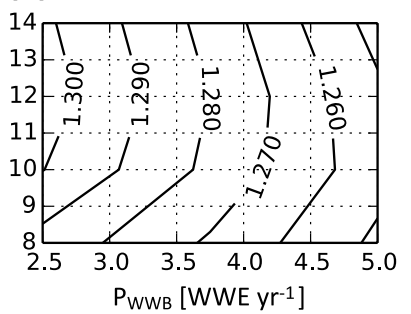

(c)

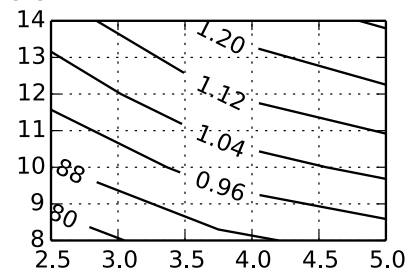

(f)

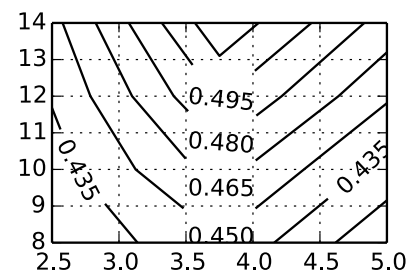

(i)

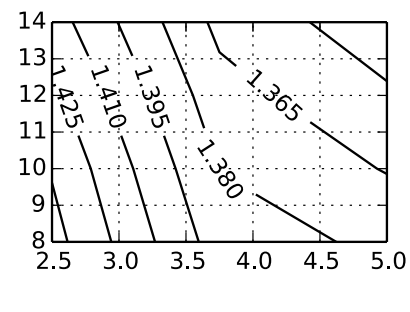

Fig. 10 Standard deviation of Niño-3 index (a-c), correlation coefficient between monthly standard deviation of Niño-3 index modeled and observed (d-f), and division of maximum by minimum monthly standard deviation of Niño-3 index (g-i) for HCM1 (left), HCM1+2 (middle) and $\mathrm{HCM} 1+2_{\mathrm{S}}$ (right) simulations as function of magnitude and probability of WWB

had the long term mean removed and the resulting time series was also smoothed with a 3-month binomial filter to be consistent with the observed. Here we identify ENSO events for which the anomalous Niño-3.4 index exceeds one standard deviation, following Okumura and Deser (2010), however rather than focusing only on the December values our events must exceed this threshold for at least 5 consecutive months.

As expected, most observed peaks of both El Niño and La Niña events tend to occur toward the end of a calendar year from November to January (Fig. 11a). In sharp contrast, but not surprisingly, peaks in HCM1 are distributed all year round and there is no marked difference between warm and cold events (Fig. 11b) for the entire ensemble. The lack of seasonal synchronization in HCM1 is expected, as it has no mechanism incorporated to link its ENSO phase to the seasonal cycle.

As shown above the simulations including EOF2, $\mathrm{HCM} 1+2$ and $\mathrm{HCM} 1+2_{\mathrm{S}}$, do display a synchronization to the seasonal cycle which is similar to that observed (Fig. 9). Looking at the number of El Niño event peaks for each calendar month in $\mathrm{HCM} 1+2$ and $\mathrm{HCM} 1+2_{\mathrm{S}}$, both show that most El Niño event peaks occur between November and January (Fig. 11c, d) consistent with that seen in 

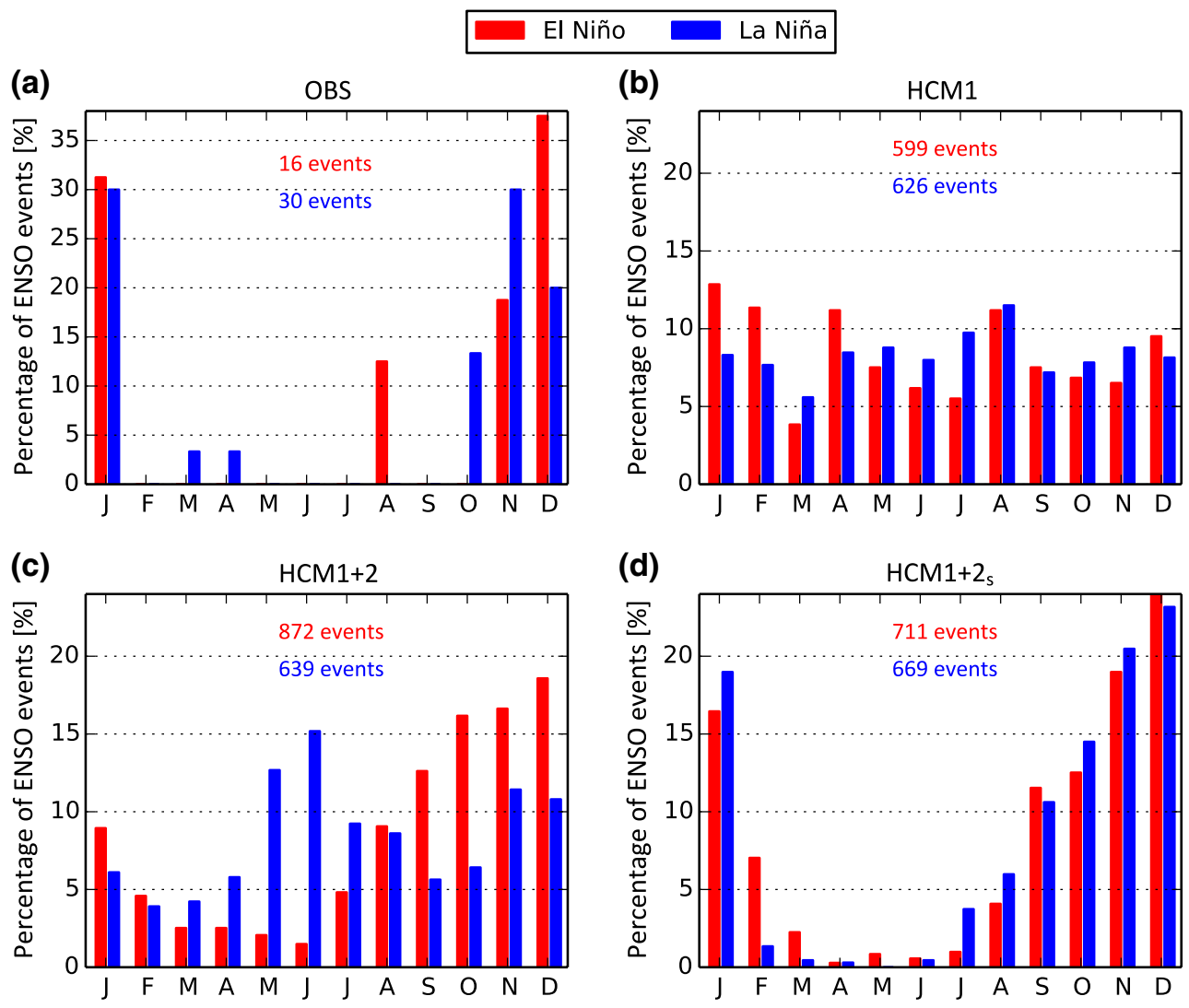

Fig. 11 Monthly peaks of El Niño (red) and La Niña (blue) events in observations (a) and the three different versions of HCM: HCM1 (b), $\mathrm{HCM} 1+2(\mathbf{c})$, and $\mathrm{HCM} 1+2 \mathrm{~S}(\mathbf{d})$. Note that number of El Niño and

the observations (Fig. 11a). However, there are some clear differences between $\mathrm{HCM} 1+2$ and $\mathrm{HCM} 1+2 \mathrm{~S}$ and with the observations, when looking at the number of La Niña event peaks for each calendar month. For instance, while both $\mathrm{HCM} 1+2_{\mathrm{S}}$ and the observations show that most $\mathrm{La}$ Niña event peaks occur between November and January, the HCM1+2 simulations suggest that most La Niña peaks occur during two periods of time in May-August and November-December. This difference helps to explain the weaker range of monthly ENSO variability seen in HCM1+2 compared to that seen in HCM1+2S (Fig. 9).

Bearing in mind that both $\mathrm{HCM} 1+2$ and $\mathrm{HCM} 1+2 \mathrm{~S}$ incorporate EOF2 (the southward wind shift), their differences must be due to the relationship between PC1 and PC2 for La Niña (negative PC1 values) events (Fig. 4). During JJA of a moderate La Niña type event (PC1 -1.5), PC2 from both HCMs display positive PC2 values that indicates the northward location of the related anomalous wind stresses. During DJF, on the other hand, $\mathrm{HCM} 1+2_{\mathrm{S}}$ displays strong negative values of $\mathrm{PC} 2(\sim-1)$, which indicates the southward location of the anomalous wind stresses and higher magnitude of these anomalies. As shown above, this
La Niña events is indicated in red and blue, respectively, at the top of each panel

southward wind shift would enhance the recharge of heat, acting to terminate the event and leading to its apparent synchronization with the seasonal cycle. HCM1+2, however, still displays positive values (although smaller than in JJA), indicating that the anomalous wind stresses still remain in a northward location relative to the wind stresses of EOF1 (Fig. 2a). Thus, the relatively minor southward wind shift that occurs in HCM1+2 during La Niña events does not act to synchronize the events to the seasonal cycle.

\subsection{Duration asymmetry}

It is generally accepted that there is an asymmetry in the duration of the two phases of ENSO events, with La Niña events lasting longer than El Niño events (Larkin and Harrison 2002; McPhaden and Zhang 2009; Obha and Ueda 2009; Okumura and Deser 2010; Okumura et al. 2011; DiNezio and Deser 2014). Given that McGregor et al. (2013) proposed that the asymmetries in the southward wind shift (e.g., El Niño event magnitude is strongly related to the extent of the meridional wind movement, while the meridional wind movement during La Niña events remains relatively small 


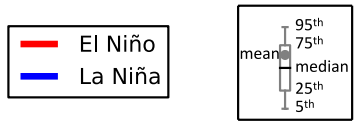

(a)
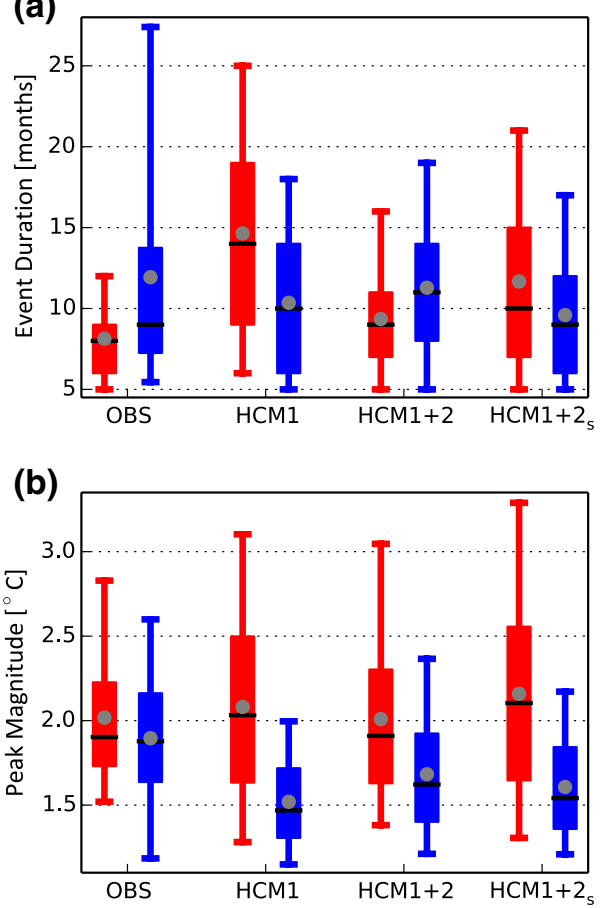

Fig. 12 Box plots of duration (a) and peak magnitude (b) of El Niño (red) and La Niña (blue) events for observations and the three different versions of HCM (HCM1, HCM1+2 and HCM1+2s). Boxes indicate the 25th and 75th values and caps the 5th and 95th ones. Medians (means) values are highlighted by solid black lines (gray circles). Note that the magnitudes of La Niña peaks are multiplied by minus one

regardless of the event magnitude) may play a role in this asymmetric duration, here we examine the ensemble of HCM simulations in an attempt to validate this proposal.

The boxplots in Fig. 12a, b show the range in durations and magnitudes, respectively, of El Niño and La Niña events, with the event duration defined as the number of months of normalized Niño-3.4 index (Sect. 5.2) exceeds one standard deviation, while the magnitude is defined at the event peak which follows the definition of Sect. 5.2. To determine whether the mean differences are significant in the duration and magnitude of events amongst the HCMs, we perform a Welch's $t$ test (Welch 1947), which does not assume equal population variance. We also assess how these duration changes play out temporally by compositing the ensemble Niño-3.4 indexes during the 3-year period (12 and 24 months before and after the peaks, respectively) around the event peak (Fig. 13) for all simulations and those observed for comparison.

The boxplot of El Niño event duration (Fig. 12a) and composite of these events for HCM1 (Fig. 13a) reveals events that extend out to over two years and that are on average 6 months longer that observed. This duration difference comes about in spite of HCM1 event magnitudes having no significant differences when compared to observed event amplitude (Fig. 12b). Interestingly, the HCM1 composite reveals that a cool state generally follows El Niño events by 18 months (Fig. 13a), giving the modeled ENSO a 3-year period. This suggests that the boreal summer peak of La Niña events in the HCM1+2 ensemble could simply reflect that warm events are forced to peak in boreal winter via EOF2, while the trailing cool event peak (which has minimal meridional wind movement) is largely only reliant on the ocean dynamical negative feedbacks of the HCM1 simulation. We also note that all versions of the HCM generate warm events stronger than cold events as observed (Fig. 12b) (Hoerling et al. 1997; Burgers and Stephenson 1999; Timmermann and Jin 2002; Jin et al. 2003; Hannachi et al. 2003; An and Jin 2004; Monahan and Dai 2004; Rodgers et al. 2004; Dong 2005).

Comparing the duration of El Niño events of HCM1+2 and $\mathrm{HCM} 1+2 \mathrm{~S}$ with those of HCM1, we find that the inclusion of EOF2 in the HCMs (i.e., HCM1+2 and HCM1+2s) results in warm events having a significantly shorter duration (Fig. 12a; Table 2). For instance, El Niño events in HCM1+2 are on average 5 months shorter than those of $\mathrm{HCM} 1$, while the events of $\mathrm{HCM} 1+2 \mathrm{~S}$ are on average 3 months shorter. This result is consistent with the results of Sect. 4, shown in Figs. 5 and 8. The HCM1+2 composite on average matches the observed composite very well during event build-up, peak and through the early stages of decay (Fig. 13c). In fact, the average El Niño duration in HCM1+2 and observations are not significantly different (Table 2). The HCM1+2s composite also matches the observed composite reasonably well in the months close to the events peak (Fig. 13e). It is noticeable, however, that both the average duration and magnitude of the events in $\mathrm{HCM} 1+2_{\mathrm{S}}$ are significantly longer/larger than those observed (Table 2; Fig. 12), which is consistent with the results of Sect. 4 (Fig. 5). The largest differences between the composites of the HCMs that include EOF2 (HCM1+2 and $\mathrm{HCM} 1+2 \mathrm{~S}$ ) and the observations come about around the trailing minimum peak, as there is clearly not as strong of a tendency in both of the HCMs for La Niña events to follow 12 months after El Niño events as the La Niña events tend to follow by 18 months (Fig. 13c, e).

Unlike warm event duration, the cool event duration response of the HCM simulations which include EOF2 depends on how the southward wind shift (EOF2) has been added. For instance, La Niña events in HCM1+2 $(\mathrm{HCM} 1+2 \mathrm{~S})$ are significantly longer (shorter) than in HCM1. However, the three mean values are only slightly different $(10.4,11.3$ and 9.6 months for HCM1, HCM1+2 and $\mathrm{HCM} 1+2 \mathrm{~s}$ respectively). In regards to their magnitudes, the inclusion of the southward wind shift in both 
Fig. 13 Composites of time series of SSTA in Niño-3.4 region during 12 (24) months prior (after) peaks for El Niño (a, c, e) and La Niña (b, d, f). The shaded areas represent the 5th and 95th envelopes of values. Solid lines indicate the mean values (a)

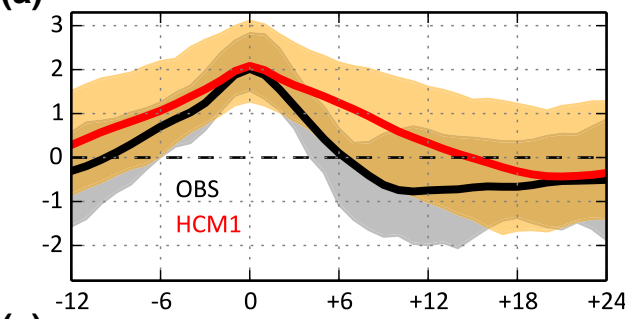

(c)

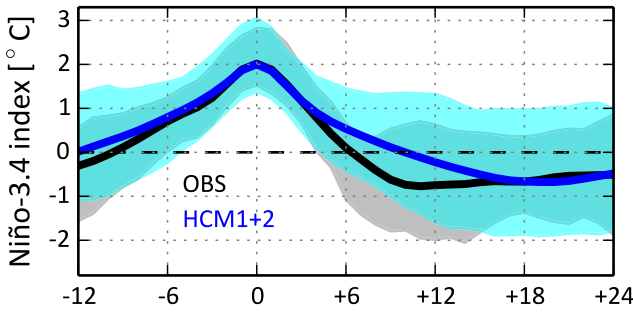

(e)

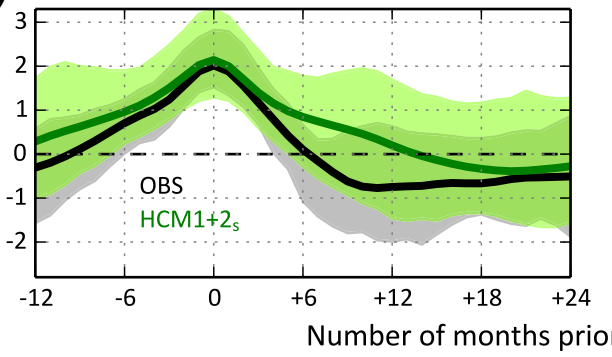

(b)

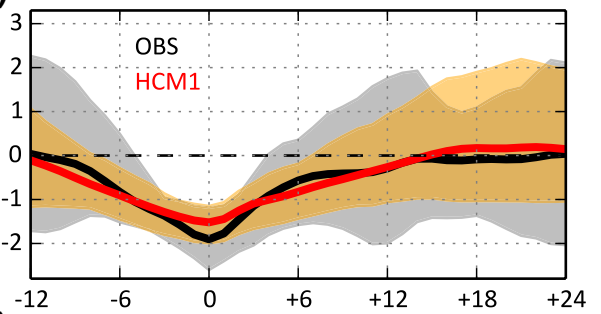

(d)

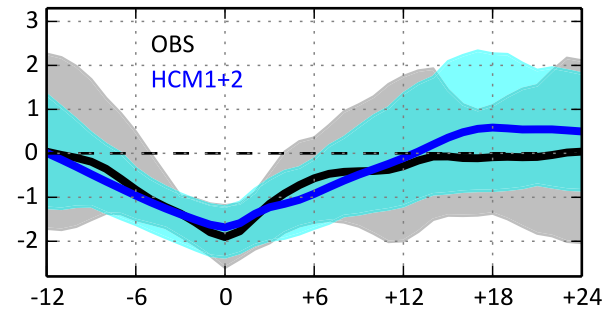

(f)

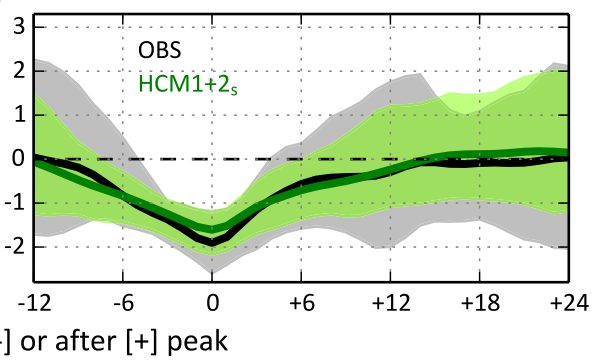

Table 2 Differences between the mean values of ENSO duration (above diagonal) in months and magnitude (below diagonal) in Kelvin amongst observations and all HCMs. Note that values are the result of the subtraction between each column and each row

\begin{tabular}{lllllllll}
\hline & EN obs & LN obs & EN HCM1 & LN HCM1 & EN HCM1+2 & LN HCM1+2 & EN HCM1+2 & LN HCM1+2s \\
\hline LN HCM1+2S & $-\mathbf{1 . 5}$ & 2.3 & $\mathbf{5 . 1}$ & $\mathbf{0 . 8}$ & -0.2 & $\mathbf{1 . 7}$ & $\mathbf{2 . 0}$ & - \\
EN HCM1+2s & $-\mathbf{3 . 5}$ & 0.3 & $\mathbf{3 . 0}$ & $-\mathbf{1 . 3}$ & $-\mathbf{2 . 3}$ & -0.4 & - & $\mathbf{0 . 6}$ \\
LN HCM1+2 & $-\mathbf{3 . 2}$ & 0.7 & $\mathbf{3 . 4}$ & $-\mathbf{0 . 9}$ & -1.9 & - & $-\mathbf{0 . 5}$ & $\mathbf{0 . 1}$ \\
EN HCM1+2 & -1.2 & 2.6 & $\mathbf{5 . 3}$ & $\mathbf{1 . 0}$ & - & $\mathbf{0 . 3}$ & $-\mathbf{0 . 2}$ & $\mathbf{0 . 4}$ \\
LN HCM1 & $-\mathbf{2 . 2}$ & 1.6 & $\mathbf{4 . 3}$ & - & $-\mathbf{0 . 5}$ & $-\mathbf{0 . 2}$ & $-\mathbf{0 . 6}$ & $-\mathbf{0 . 1}$ \\
EN HCM1 & $-\mathbf{6 . 5}$ & -2.7 & - & $\mathbf{0 . 6}$ & $\mathbf{0 . 1}$ & $\mathbf{0 . 4}$ & $-\mathbf{0 . 1}$ & $\mathbf{0 . 5}$ \\
LN obs & $-\mathbf{3 . 8}$ & - & $-\mathbf{0 . 2}$ & $\mathbf{0 . 4}$ & -0.1 & $\mathbf{0 . 2}$ & $-\mathbf{0 . 3}$ & $\mathbf{0 . 3}$ \\
EN obs & - & 0.1 & -0.1 & $\mathbf{0 . 5}$ & 0.0 & $\mathbf{0 . 3}$ & -0.1 & $\mathbf{0 . 4}$ \\
\hline
\end{tabular}

Bold (italic) values indicate that the difference is significant at the $95 \%(90 \%)$ level, as judged by a Welch's $t$ test

HCM1+2 and HCM1+2S) makes La Niña events significantly larger than in HCM1 (Table 2).

\section{Discussion and conclusions}

In this work we examine the role of the southward movement of ENSO's anomalous zonal winds that occurs near the end of the calendar year, when ENSO events typically reach their peak amplitude. It is shown (Figs. 1, 2, 3) that the combination of the two leading EOF of tropical Pacific wind stresses captures this meridional wind movement, consistent with previous studies (e.g., McGregor et al. 2012a). With the aim of investigating how this meridional wind movement can influence both the seasonal synchronization and duration of ENSO events, a series of hybrid coupled models (HCMs) were constructed: HCM1 (which includes EOF1 only, i.e. no southward wind shift); HCM1+2 and $\mathrm{HCM} 1+2 \mathrm{~S}$ (which both including EOF2, while the monthly coefficients are realistic and idealized, respectively).

We found that the variation of the air-sea coupling intensity from month to month, due to the meridional movement 
of ENSO winds, leads to synchronization of ENSO events with the seasonal cycle. It was shown in Sect. 4 (our idealised 1997/98 perturbation experiments) that the strong coupling during boreal summer occurs when ENSO's anomalous wind stresses are largely symmetric about the equator, while the weaker coupling during the boreal winter occurs when ENSO's anomalous wind stresses are largely asymmetric and the wind stress maximum is located between $\sim$ $5^{\circ}$ and $7^{\circ} \mathrm{S}$. The strong coupling in boreal summer allows ENSO events to grow rapidly throughout this period. Therefore, as demonstrated in Fig. 8, WWB that occur just prior to this strong coupling are the best placed to generate large ENSO events. On the other hand, the weak coupling during boreal winter limits growth and tends to discharge WWV, which enhances the termination the event. It is worth pointing out that in these idealized experiments no WWB activity occurs after the initial forcing. Thus, this result acts as a theoretical proof of the earlier work of Harrison and Vecchi (1999), Vecchi and Harrison (2003, 2006) and Lengaigne et al. (2006); and is conceptually consistent with the idealised results of Stein et al. (2014). Furthermore, it is in good agreement with that reported by Horii and Hanawa (2004), in which they noted that warm events that do not develop until late summer-fall tend to be weaker and persist longer into the second year.

In Sect. 5 we constructed three ensembles of simulations, each using a different version of the HCM, where the ensemble members differ in the timing, magnitude and probabilities of WWB. The purpose of these simulations was to more fully understand the effect of EOF2 in the tendency for ENSO events to be synchronized with the seasonal cycle. As expected, the HCM1 simulations do not exhibit any seasonal preference in the timing of ENSO events; in other words, they do not show any synchronization of ENSO events to the annual cycle. Furthermore, the duration of El Niño events are much longer (up to 6 months on average) that those observed, resulting in higher variability of SSTA over the eastern equatorial Pacific.

The realistic inclusion of EOF2 (HCM1+2), which reproduces strong (weak) southward shift of westerlies (easterlies) in DJF during El Niño (La Niña) years as observations, leads to ENSO seasonal synchronization, although the annual amplitude is weaker than that observed. Such difference (also seen in $\mathrm{HCM} 1+2 \mathrm{~S}$ ) might be associated with the stochastic WWBs, which were found to reduce the interannual variability compared to semistochastic WWBs (Gebbie et al. 2007). It is shown that El Niño events terminate abruptly in HCM1+2 after peaking near the end of the calendar year, which results in the events being significantly shorter than those of HCM1 ensemble. The minimal meridional wind movement during La Niña phases leaves the termination of these events to rely solely on the modeled oceanic wave adjustment. Therefore, cool events reach their peak amplitude at the wrong time of the year (Fig. 11c), while the relative symmetry of the wind stresses about the equator allows the events to grow larger than those of HCM1. The resulting La Niña events are on average also significantly longer than those in HCM1, however the mean difference between these two distributions is less than one month (Table 2).

The inclusion of EOF2 with idealised coefficients $(\mathrm{HCM} 1+2 \mathrm{~S})$ also results in synchronization of ENSO to the annual cycle with seasonal amplitude weaker than that observed, but also stronger than that produced in HCM1+2. The minimum variance, however, is lagged by 3 months compared to the observations. In this case, the positive EOF2 values during El Niño years in JJA acts to charge the equatorial region WWV while also making the associated westerlies more symmetric around the equator, which allows the event to grow larger, while the strong southward wind shift in DJF, similar to $\mathrm{HCM} 1+2$, enhances the termination of the warm events in the following months. Interestingly, the linearity of the simple southward shift allows this HCM to produce a strong southward shift of anomalous easterlies near the end of the calendar year during La Niña years (Fig. 4). This strong shift acts to synchronize the La Niña event peak to the seasonal cycle (Fig. 11d), consistent with the observations.

The clear difference between HCM1+2 and HCM1+2S highlighted above is in the role of the EOF2 in the synchronization of La Niña events. HCM1+2 suggests that the effect of EOF2 is small during La Niña events, as such it does not act to synchronize the events to the annual cycle and the modeled cool events peak at the wrong time of the year. $\mathrm{HCM} 1+2_{\mathrm{S}}$, on the other hand, has a strong role making the events peak at the right time of the year. While the resulting La Niña events do have a more realistic end of calendar year peak, it should be noted that the strong role of EOF2 during these events is not consistent with the observations (see Fig. 4). This implies that one of the other mechanism discussed in the introduction may be responsible for synchronizing the La Niña event peak with the seasonal cycle. However, it is worthwhile to note that there is very little data for large La Niña events so the composites are based largely around smaller magnitude events, thus the role of the southward wind shift in the duration of La Niña events is still unclear.

What has also become apparent from our study, however, is that the characteristics of WWB also have the potential to be incredibly important. In particular, the best correlation coefficients between the monthly standard deviation of Niño-3 index modeled and observed are obtained with 3.5-4.0 WWB $\mathrm{yr}^{-1}$ (Fig. 10e, f), probabilities consistent with that found in observations (e.g., Gebbie et al. 2007). In relation to the seasonal amplitude, higher values are reached for a lower frequency of WWB (Fig. 10h, i), suggesting that higher frequency WWBs (in the absence 
of any seasonality in the burst themselves) act to damp the seasonal variance changes. This result is in good agreement with previous studies, for instance Neelin et al. (2000), in which it was suggested that the atmospheric stochastic forcing might be a candidate for altering this ENSO's seasonal synchronization. This importance is perhaps most clearly apparent looking at the peak month of the El Niño event (Fig. 11c), as in the absence of WWB around the peak time all events appear to peak in DJF (Fig. 8). This suggests that while the meridional movement of winds leads to a rapid termination of El Niño events, as shown here, the effective termination of an event is also reliant on the ocean dynamics of the traditional RDO mechanism (Jin 1997). Thus, the enhanced termination of ENSO events due to the southward shift and its changes in coupling strength might be not enough to overcome poorly timed WWBs. This finding supports the earlier study of Gebbie et al. (2007), where the modeled seasonal synchronization displays a strong sensitivity of the timing of triggering WWBs.

Thus, despite the simplicity of the HCMs used in this work, we found that the southward shift of El Niño-related westerly plays a key role in having El Niño event peaks in the boreal winter, supporting previous studies (e.g., Harrison and Vecchi 1999; Vecchi and Harrison 2003; McGregor et al. 2012a; Stuecker et al. 2013). This shift also acts to shorten the modeled duration of El Niño events, while our results suggest that it plays a minimal role in the length of La Niña events. Although not mentioned as such, this shift is apparent in the Harrison and Vecchi (1997) analysis of WWEs, where they identified a clear seasonal preference for WWEs to occur north (south) of the equator during July-November (December-March) (see their Figs. 22, 23). This movement of WWBs may have the effect of enhancing the seasonal synchronization affects of the southward wind shift. Furthermore, in this study it is demonstrated that the effective termination is carried out by two components: (1) the ocean dynamics of the traditional RDO mechanism (Jin 1997); and (2) the discharge of WWV due to the southward wind shift, and both must align to some degree to allow for an abrupt event termination.

Acknowledgments This study was supported by the Australian Research Council's (ARC) through grant number DE130100663, with additional support coming via the ARC Centre of Excellence for Climate System Science. The authors would also like to thank the editor and one anonymous reviewer for the constructive comments and suggestions, which substantially improved this manuscript.

Open Access This article is distributed under the terms of the Creative Commons Attribution 4.0 International License (http://creativecommons.org/licenses/by/4.0/), which permits unrestricted use, distribution, and reproduction in any medium, provided you give appropriate credit to the original author(s) and the source, provide a link to the Creative Commons license, and indicate if changes were made.

\section{References}

An SI, Jin FF (2004) Nonlinearity and asymmetry of ENSO. J Clim 17:2399-2412

Annamalai H, Xie SP, McCreary JP, Murtugudde R (2005) Impact of Indian Ocean sea surface temperature on a developing El Niño. J Clim 18:302-319

Balmaseda MA, Davey MK, Anderson DLT (1995) Decadal and seasonal dependence of ENSO prediction skill. J Clim 8:2705-2715

Battisti DS (1988) The dynamics and thermodynamics of a warming event in a coupled tropical atmosphere-ocean model. J Atmos Sci 45:2889-2919

Bjerkness J (1969) Climatological effects of orography and land-sea heating contrasts on the gravity wave-driven circulation of the mesosphere. Mon Wea Rev 60:103-118

Burgers G, Stephenson DB (1999) The "normality" of El Niño. Geophys Res Lett 26:1027-1030

Cane MA, Zebiak S (1985) A theory for El Niño and the Southern Oscillation. Science 228:1084-1087

Chang P (2006) Climate fluctuations of tropical coupled systems- the role of ocean dynamics. J Clim 19:5122-5174

Chen D, Lian T, Fu C, Cane MA, Tang Y, Murtugudde R, Song X, Wu Q, Zhou L (2015) Strong influence of westerly wind bursts on El Niño diversity. Nat Geosci 8:339-345

Chen SS, Houze RA, Mapes BE (1996) Multiscale variability of deep convection in relation to large-scale circulation in TOGA COARE. J Atmos Sci 53:1380-1409

Chu PS (1988) Extratropical forcing and the burst of equatorial westerlies in the western Pacific: a synoptic study. J Meteorol Soc Jpn 66:4549-4564

Dee DP, Uppala SP (2009) Variational bias correction of satellite radiance data in the ERA-Interim reanalysis. Q J R Meteorol Soc 135:1830-1841

Deser C et al. (2012) ENSO and Pacific decadal variability in the Community Climate System Model version 4. J Clim 25:26222651. doi:10.1175/JCLI-D-11-00301.1

DiNezio PN, Deser C (2014) Nonlinear controls on the persistence of La Niña. J Clim 27:7335-7355

Dong BW (2005) Asymmetry between El Niño and La Niña in a global coupled GCM with and eddy-permitting ocean resolution. J Clim 18:3084-3098

Eisenman I, Yu L, Tziperman E (2005) Westerly wind bursts: ENSO's tail rather than the dog? J Clim 18:5224-5238

Frauen C, Dommenget D (2010) El Niño and La Niña amplitude asymmetry caused by atmospheric feedbacks. Geophys Res Lett 37:L18801. doi:10.1029/2010GL044444

Galanti E, Tziperman E, Harrison M, Rosati A, Giering R, Sirkes Z (2002) The equatorial thermocline outcropping - a seasonal control on the tropical Pacific Ocean-atmosphere instability strength. J Clim 15:2721-2739

Gebbie G, Tziperman E (2009) Predictability of SST-modulated westerly wind bursts. J Clim 22:3894-3909

Gebbie G, Eisenman I, Wittenberg A, Tziperman E (2007) Modulation of westerly wind bursts by sea surface temperature: a semistochastic feedback for ENSO. J Atmos Sci 64:3281-3295

Giese B, Harrison D (1991) Eastern equatorial Pacific response to three composite westerly wind types. J Geophys Res 96:3239-3248

Giese B, Harrison DE (1990) Aspects of the Kelvin wave response to episodic wind forcing. J Geophys Res 95:7289-7312

Graham N, White W (1988) The El Niño cycle: a natural oscillator of the Pacific ocean-atmosphere system. Science 240:1293-1302

Ham YG, Kug JS (2014) ENSO phase-locking to the boreal winter in CMIP3 and CMIP5 models. Clim Dyn 43:305-318

Ham YG, Kug JS, Kim D, Kim YH, Kim DH (2013) What controls phase-locking of ENSO to boreal winter in coupled GCMs? Clim Dyn 40:1551-1568 
Hannachi A, Stephenson D, Sperber K (2003) Probability-based methods for quantifying nonlinearity in the ENSO. Clim Dyn 20:241-256

Harrison DE (1987) Monthly mean island surface winds in the central tropical Pacific and El Niño events. Mon Wea Rev 115:3133-3145

Harrison DE, Larkin NK (1998) Seasonal U.S. temperature and precipitation anomalies associated with El Niño: historical results and comparison with 1997-1998. Geophys Res Lett 25:3959-3962

Harrison DE, Vecchi GA (1997) Surface westerly wind events in the tropical Pacific 1986-1995. J Clim 10:3131-3156

Harrison DE, Vecchi GA (1999) On the termination of El Niño. Geophys Res Lett 26:1593-1596

Hirst A (1986) Unstable and damped equatorial modes in simple coupled ocean-atmosphere models. J Atmos Sci 43:606-632

Hoerling M, Kumar A, Zhong M (1997) El Niño, La Niña, and the nonlinearity of their teleconnections. J Clim 10:1769-1786

Horii T, Hanawa K (2004) A relationship between timing of El Niño onset and subsequent evolution. Geophys Res Lett 31:L06304. doi:10.1029/2003GL019239

Jin FF (1997) An equatorial ocean recharge paradigm for ENSO. Part I: conceptual model. J Atmos Sci 54:811-829

Jin FF, Neelin J, Ghil M (1994) El Niño on the devil's staircase: annual subharmonic steps to chaos. Science 264:70-72

Jin FF, An SI, Timmermann A, Zhao J (2003) Strong El Niño events and nonlinear dynamic heating. Geophys Res Lett 30:1120. doi: 10.1029/2002GL016356

Keen RA (1982) The role of cross-equatorial cyclone pairs in the Southern Oscillation. Mon Wea Rev 110:1405-1416

Kerr RA (1999) Atmospheric science: does a globe-girdling disturbance jigger El Niño? Science 285:322-323

Kessler WS, Kleeman R (2000) Rectification of the Madden-Julian Oscillation into the ENSO Cycle. J Clim 13:3560-3575

Kleeman R (1993) On the dependence of hincast skill on ocean thermodynamics in a coupled ocean-atmosphere model. J Clim 6:2012-2033

Kug JS, Kang IS (2006) Interactive feedback between ENSO and the Indian Ocean. J Clim 19:1784-1801

Larkin NK, Harrison DE (2002) ENSO warm (El Niño) and cold (La Niña) event lifecycles: ocean surface anomaly patterns, their symmetries, asymmetries, and implications. J Clim 15:1118

Latif M, Biercamp J, von Storch H (1988) The response of a coupled ocean-atmosphere general circulation model to wind bursts. J Atmos Sci 45:964-979

Lengaigne M, Vecchi GA (2009) Contrasting the termination of moderate and extreme El Niño events in coupled general circulation models. Clim Dyn. doi:10.1007/s00382-009-2562-3

Lengaigne M, Guilyardi E, Boulanger JP, Menkes C, Delecluse P, Inness P, Cole J, Slingo J (2004) Triggering of El Niño by westerly wind events in a coupled general circulation model. Clim Dyn 23:601-620

Lengaigne M, Boulanger J, Meinkes C, Spencer H (2006) Influence of the seasonal cycle on the termination of El Niño events in a coupled general circulation model. J Clim 19:1850-1868

Lorenz EN (1956) Empirical orthogonal functions and statistical weather prediction. Science report no. 1, statistical forecasting project. MIT Press, Cambridge, MA, 48 pp

McGregor S, Timmermann A, Schneider N, Stuecker MF, England MH (2012) The effect of the South Pacific Convergence Zone on the termination of El Niño events and the meridional asymmetry of ENSO. J Clim 25:5566-5586

McGregor S, Gupta AS, England M (2012b) Constraining wind stress products with sea surface height observations and implications for Pacific ocean sea level trend attribution. J Clim 25:8164-8176
McGregor S, Ramesh N, Spence P, England MH, McPhaden MJ, Santoso A (2013) Meridional movement of wind anomalies during ENSO events and their role in event termination. Geophys Res Lett 40:749-754

McGregor S, Spence P, Schwarzkopf FU, England MH, Santoso A, Kessler WS, Timmermann A, Böning CW (2014) ENSOdriven interhemispheric Pacific mass transports. J Geophys Res Oceans. doi:10.1002/2014JC010286

McPhaden MJ (1999) Genesis and evolution of the 1997-98 El Niño. Science. doi:10.1126/science.283.5404.950

McPhaden MJ (2004) Evolution of the 2002/03 El Niño. Bull Am Meteorol Soc 85:677-695

McPhaden MJ, Zhang X (2009) Asymmetry in zonal phase propagation of ENSO sea surface temperature anomalies. Geophys Res Lett 36:L13703. doi:10.1029/2009GL038774

McPhaden MJ, Zebiak SE, Glantz MH (2006) ENSO as an integrating concept in earth science. Science 314:1740-1745

Meinen CS, McPhaden MJ (2000) Observations of warm water volume changes in the equatorial Pacific and their relationship to El Niño and La Niña. J Clim 13:3551-3559

Monahan AH, Dai A (2004) The spatial and temporal structure of ENSO nonlinearity. J Clim 17:3026-3036

Neelin JD, Battisti DS, Hirst AC, Jin FF, Wakata Y, Yamagata T, Zebiak SE (1998) ENSO theory. J Geophys Res 103:14261-14290

Neelin JD, Jin FF, Syu HH (2000) Variations in ENSO phase locking. J Clim 13:2570-2590

Obha M, Ueda H (2007) An impact of SST anomalies in the Indian Ocean in acceleration of the El Niño to La Niña transition. J Meteorol Soc Jpn 85:335-348

Obha M, Ueda H (2009) Role of nonlinear atmospheric response to SST on the asymmetric transition process of ENSO. J Clim 22:177-192

Okumura YM, Deser C (2010) Asymmetry in the duration of El Niño and La Niña. J Clim 23:5826-5843

Okumura YM, Masamichi O, Clara D, Hiroaki U (2011) A proposed mechanism for the asymmetric duration of El Niño and $\mathrm{La}$ Niña. J Clim 24:3822-3829

Philander S, Yamagata T, Pacanowski R (1984) Unstable air-sea interactions in the tropics. J Atmos Sci 41:604-613

Philander SG (1983) El Niño Southern Oscillation phenomena. Nature 302:295-301. doi:10.1038/302295a0

Philander SG (1990) El Niño, La Niña, and the Southern Oscillation. Academic Press, Waltham

Rasmusson E, Carpenter T (1982) Variations in tropical sea surface temperature and surface wind fields associated with the Southern Oscillation/El Niño. Mon Wea Rev 110:353-384

Rebert JP, Donguy JR, Eldin G (1985) Relations between sea level, thermocline depth, heat content and dynamic height in the tropical Pacific Ocean. J Geophys Res 90:11,719-11,725

Rodgers KB, Friederichs P, Latif M (2004) Tropical Pacific decadal variability and its relation to decadal modulations of ENSO. J Clim 17:3761-3774

Ropelewski CH, Halpert S (1989) Precipitation patterns associated with the high index phase of the southern oscillation. J Clim 2:268-284

Smith TM, Reynolds RW, Peterson TC, Lawrimore J (2008) Improvements to NOAA's historical merged land-ocean surface temperature analysis (1880-2006). J Clim 21:2283-2296

Smith WHF, Sandwell DT (1997) Global sea floor topography from satellite altimetry and ship depth soundings. Science 277:1956-1962

Stein K, Timmermann A, Schneider N (2014) ENSO seasonal synchronization theory. J Clim 27:5285-5310

Stuecker MF, Timmermann A, Jin FF, McGregor S, Ren HL (2013) A combination mode of the annual cycle and the El Niño/Southern Oscillation. Nat Geosci 6:540-544 
Stuecker MF, Jin FF, Timmermann A, McGregor S (2015) Combination mode dynamics of the anomalous northwest Pacific anticyclone. J Clim 28:1093-1111

Takahashi K, Montecinos A, Goubanova K, Dewitte B (2011) ENSO regimes: Reinterpreting the canonical and Modoki El Niño. Geophys Res Lett 38:L10704

Timmermann A, Jin FF (2002) Phytoplankton influences on tropical climate. Geophys Res Lett 29: doi:10.1029/2002GL015434

Tomczak M, Godfrey SJ (1994) Regional oceanography: an introduction. Pergamon Press, Oxford

Torrence C, Webster PJ (1998) The annual cycle of persistence in the El Niño/Southern Oscillation. Q J R Meteorol Soc 124:1985-2004

Trenberth KE (1997) The definition of El Niño. Bull Am Meteorol Soc 78:2771-2777

Trenberth KE, Stepaniak DP (2001) Indices of El Niño evolution. J Clim 14:1697-1701

Trenberth KE, Branstator GW, Karoly D, Kumar A, Lau NC, Ropelewski C (1998) Progress during TOGA in understanding and modeling global teleconnections associated with tropical sea surface temperatures. J Geophys Res 103:14291-14324

Tziperman E, Stone E, Cane M, Jarosh H (1994) El Niño chaos: Overlapping of resonances between the seasonal cycle and the Pacific ocean-atmosphere oscillator. Science 264:72-74

Tziperman E, Zebiak S, Cane M (1997) Mechanisms of seasonalENSO interaction. J Atmos Sci 54:61-71

Vecchi G, Harrison D (2000) Tropical Pacific sea surface temperature anomalies, El Niño, and equatorial westerly wind events. J Clim 13:1814-1830

Vecchi G, Harrison DE (2003) On the termination of the 2002-03 El Niño event. Geophys Res Lett 30:1964

Vecchi GA (2006) The termination of the 1997-98 El Niño. Part II: Mechanisms of atmospheric change. J Clim 19:2647-2664

Vecchi GA, Harrison DE (2006) The termination of the 19971998 El Niño. Part I: mechanisms of oceanic change. J Clim 19:2633-2646

Verbickas S (1998) Westerly wind bursts in the tropical Pacific. Weather 53:282-284
Wang B, Wu R, Lukas R (1999) Roles of the western North Pacific wind variation in thermocline adjustment and ENSO phase transition. J Meteorol Soc Jpn 77:1-16

Wang X, Jin FF, Wang Y (2003) A tropical ocean recharge mechanism for climate variability. Part I: equatorial heat content changes induced by the off-equatorial wind. J Clim 16:3585-3598

Welch BL (1947) The generalization of 'Student's' problem when several different population variances are involved. Biometrika 34:28-35

Wyrtki K (1975) El Niño-the dynamic response of the equatorial Pacific ocean to atmospheric forcing. J Phys Oceanogr 5:572-584

Wyrtki K, Meyers G (1976) The trade wind field over the Pacific Ocean. J Appl Meteorol 15:698-704

Yamanaka G, Yasuda T, Fujii Y, Matsumoto S (2009) Rapid termination of the 2006 El Niño and its relation to the Indian Ocean. Geophys Res Lett 36:L07702. doi:10.1029/2009GL037298

Yan B, Wu R (2007) Relative roles of different components of the basic state in the phase locking of El Niño mature phases. J Clim 20:4267-4277

Yoo SH, Fasullo J, Yang S, Ho CH (2010) On the relationship between Indian Ocean sea surface temperature and the transition from $\mathrm{El}$ Niño to La Niña. J Geophys Res. doi:10.1029/2009JD012978

Yu L, Rienecker MM (1998) Evidence of an extratropical atmospheric influence during the onset of the 1997-98 El Niño. Geophys Res Lett 25:3537-3540

Yu L, Weller RA, Liu TW (2003) Case analysis of a role of ENSO in regulating the generation of westerly wind bursts in the western equatorial Pacific. J Geophys Res 108:3128. doi:10.1029/200 2JC001498

Zebiak SE, Cane MA (1987) A model of El Niño-Southern Oscillation. Mon Wea Rev 115:2262-2278

Zelle H, Appeldoorn G, Burgers G, Oldenborgh GJV (2004) The relationship between sea surface temperature and thermocline depth in the eastern equatorial Pacific. J Phys Oceanogr 34:643-655

Zhang C (1996) Atmospheric intraseasonal variability at the surface in the tropical western Pacific Ocean. J Atmos Sci 53:739-758 